\title{
Complutum
}

ISSN: 1131-6993

\section{Puertas hacia el mundo simbólico: una nueva propuesta interpretativa acerca de los recintos de taula de Menorca}

\author{
Antoni Ferrer Rotger ${ }^{1}$; Irene Riudavets González ${ }^{2}$; Gerard Remolins Zamora ${ }^{3}$; Cristina Bravo Asensio ${ }^{4}$
}

Resumen. Durante la segunda Edad del Hierro se construyen en Menorca unos edificios singulares conocidos como recintos de taula. La estructura central de estos espacios ha sido objeto de numerosas hipótesis a lo largo del siglo $\mathrm{XX}$, destacando su interpretación simbólica. Por el contrario, los espacios domésticos de la misma cronología, con un elevado grado de estandarización, han sido estudiados sobre todo desde la vertiente funcional. En el presente trabajo se comparan los dos tipos de estructuras, planteando que ambas responden a una misma concepción ideológica del espacio. A partir de esta comparativa, se propone que las taulas son representaciones monumentales del acceso a la habitación norte de los espacios domésticos, simbolizando una entrada al espacio sagrado. El análisis estadístico de las proporciones de los elementos constitutivos de puertas y taulas, aunque no es concluyente, permite afirmar que existe una similitud arquitectónica entre ambos elementos. Finalmente, se plantea que el correlato entre casas y recintos de taula constituye un modo de legitimación de las estructuras sociales por parte de las comunidades que construyeron estas estructuras.

Palabras clave: Menorca; cultura talayótica; arquitectura doméstica; arquitectura religiosa; simbolismo; estadística.

\section{[en] Doors to a symbolic world: a new interpretative proposal on taula enclosures from Menorca}

Abstract. Singular buildings known as taula enclosures were built in Menorca in the second Iron Age. The central structure of these spaces has been the object of numerous hypotheses during the 20th century, most of them aiming at shedding light on its symbolic interpretation. On the contrary, domestic spaces, which were built in the same period and present a high level of standardisation, have been mostly studied on the aspect of their function. In this paper, the two types of structures are compared, suggesting that both respond to the same ideological conception of space. From this comparison, it is suggested that the taula is the monumental representation of the door that gives access to the northern room in domestic spaces, representing an entrance to the sacred space. The statistical analysis of the proportions of the constitutive elements of doors and taulas, despite not being conclusive, allows for stating that there is an architectural similarity between these two elements. Finally, it is suggested that the analogy between dwellings and taula enclosures constitutes a means of legitimation of the social structures by the communities who built them.

Keywords: Menorca; Talayotic culture; domestic architecture; religious architecture; symbolism; statistics.

Sumario. 1. Introducción: la Edad del Hierro en Menorca. 2. Los recintos de taula: aspectos generales. 3. Comparativa entre los recintos de taula y las casas de planta circular. 3.1. Aspectos cualitativos. Análisis de similitud entre taulas y puertas. 3.2.1. Metodología. 3.2.2. Descripción de la muestra y selección de las variables. 3.2.3. Análisis de la similitud. 3.2.4. Resultados. 4. Discusión. 5. Conclusiones. Bibliografía.

Cómo citar: Ferrer Rotger, A.; Riudavets González, I.; Remolins Zamora, G.; Bravo Asensio, C. (2020). Puertas hacia el mundo simbólico: una nueva propuesta interpretativa acerca de los recintos de taula de Menorca. Complutum, 31 (1): $139-158$.

I Institut Menorquí d'Estudis, Camí des Castell, 28, 07702, Maó.

Correo e.: antoniferrer1@gmail.com. Telf: 655787657

2 Doctoranda del programa Societat i Cultura: Història, Antropologia, Art i Patrimoni de la Universitat de Barcelona.

NURARQ: Menorca, Arqueologia i Cultura, C/ Alaior 10B, 07760, Ciutadella de Menorca.

Correo e.: irene.riudavets@nurarq.com

3 Doctorando Erasmus Mundus en Quaternari i Prehistòria de la Universistat Rovira i Virgili.

ReGiraRocs SLU. Recerca, Conservació i Difusió del Patrimoni Cultural i Natural dels Pirineus. Av. Carlemany 115, AD700 Escaldes-Engordany, Principat d'Andorra.

Correo e.: info@regirarocs.com.

4 NURARQ: Menorca, Arqueologia i Cultura, C/ Alaior 10B, 07760, Ciutadella de Menorca. cristina.bravo@nurarq.com 


\section{Introducción: la Edad del Hierro en Menorca}

Menorca es la más septentrional de la Islas Baleares y la más alejada de las costas continentales (Fig. 1). Durante gran parte del segundo milenio cal BC, la cultura material de las comunidades humanas de esta isla es prácticamente idéntica a la de los habitantes de Mallorca (Albero et al. 2011). A finales del segundo milenio cal $\mathrm{BC}$ se iniciará un proceso de divergencia cultural entre ambas islas. Se trata de la fase conocida como Prototalayótico (Micó 2005) o Talayótico Inicial (Anglada et al. 2017). Dicha diferenciación se acentuará a mediados del primer milenio cal BC. Pese a todo, las dos islas seguirán compartiendo, a lo largo de toda su prehistoria, muchos rasgos culturales, de forma que la mayoría de los autores utilizan la misma terminología para referirse a las diferentes etapas cronoculturales de las dos islas (e.g. Rosselló-Bordoy 1973; Waldren 1986; Plantalamor 1991; Micó 2005; Salvà y Hernández-Gasch 2007).

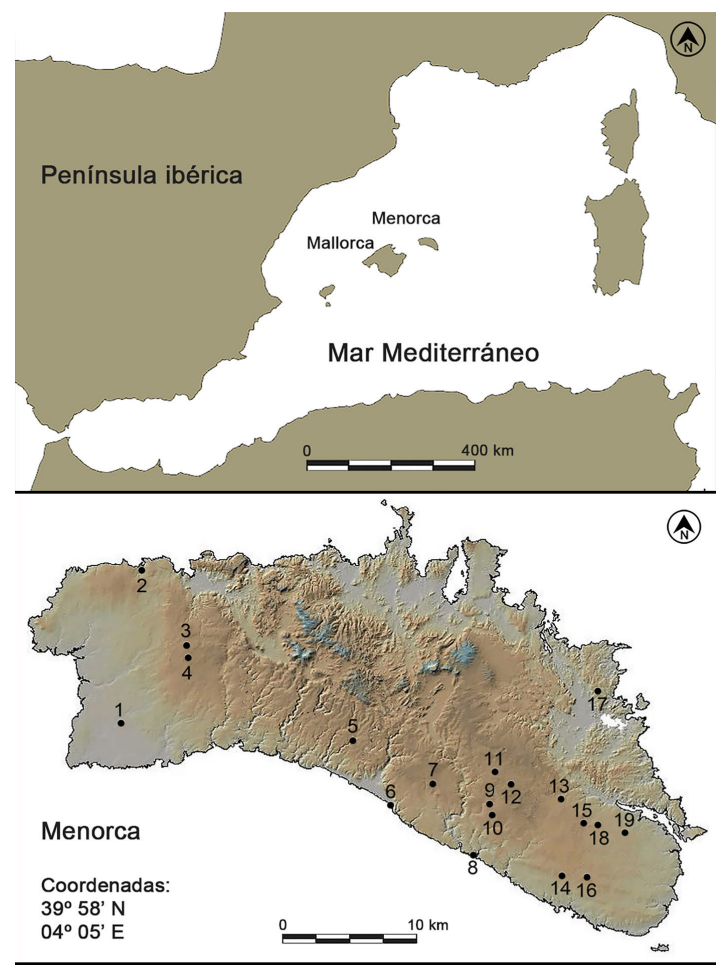

1 Son Catlar, 2 Cala Morell, 3 Torrellafuda, 4 Torretrencada, 5 Santa Mònica, 6 Son Bou, 7 Torre d'en Galmés, 8 Cales Coves, 9 Torrellisar, 10 So na Caçana, 11 Torralba d'en Salort, 12 Cotaina, 13 Talatí de Dalt, 14 Biniparratxet, 15 Cornia Nou, 16 Binissafullet, 17 Sa Torreta de Tramuntana, 18 Sa Cudia Cremada, 19 Trepucó

Figura 1. Ubicación de la isla de Menorca y de los yacimientos arqueológicos citados en el texto.
En ambas islas, la segunda Edad del Hierro se extiende, a grandes rasgos, entre el siglo VI a.C. y la conquista romana en el año 123 a.C., periodo que se ha denominado Postalayótico (e.g. Waldren 1986; Micó 2005) Baleárico (Salvà y Hernández -Gasch 2007) o Talayótico Final (e.g. Rosselló-Bordoy 1973; Plantalamor 1991; Anglada et al. 2017). Esta última denominación es la que se utilizará en este trabajo. Durante esta etapa el mundo indígena intensifica sus intercambios con el exterior, especialmente con las zonas de influencia púnica. El síntoma más visible de estos contactos es la llegada, masiva a partir de los siglos IVIII a.C., de materiales cerámicos provenientes de Ibiza.

Los datos disponibles indican que la economía de Menorca durante este periodo se basa en la ganadería de ovicaprinos y, en menor medida, bovinos y suidos (Ramis 2017) así como en el cultivo de cereales (e.g. Portillo et al. 2014). Se ha propuesto que estas actividades económicas se inserirían en el contexto de una sociedad fuertemente estratificada (Guerrero et al. 2006).

Pese a las influencias externas, gran parte de los rasgos culturales de las comunidades menorquinas de este periodo, tanto tecnológicos como ideológicos, son de tradición claramente indígena y entroncan con la fase precedente. Así, la técnica constructiva, de carácter ciclópeo, las técnicas alfareras y los sistemas de preparación de alimentos continuarán siendo de tradición local (Anglada et al. 2017b). La estructuración de los asentamientos sobre el territorio no presenta asimismo ninguna ruptura significativa respecto a la fase anterior, documentándose una gran continuidad en la ocupación de los núcleos de población (e.g. Smith y Van Dommelen 2018). Respecto a los espacios funerarios, la mayor parte de ellos siguen siendo, como en la fase precedente, de tipo colectivo, si bien es cierto que durante esta etapa aparecen grandes necrópolis de hipogeos en los acantilados y barrancos de la isla, como Son Bou o Calescoves, con ajuares que evidencian rituales cada vez más complejos (Veny 1982).

Los espacios domésticos menorquines de esta etapa, denominados círculos o casas de planta circular, presentan una fuerte estandarización, y responden a una tipología exclusiva de la isla. Se trata de grandes edificios ciclópeos con planta de tendencia circular, que presentan un patio central alrededor del cual 
se sitúan, de forma radial, entre cinco y siete habitaciones (Pons 2016; Sintes y Isbert 2009) (Figs. 2 y 3 ).
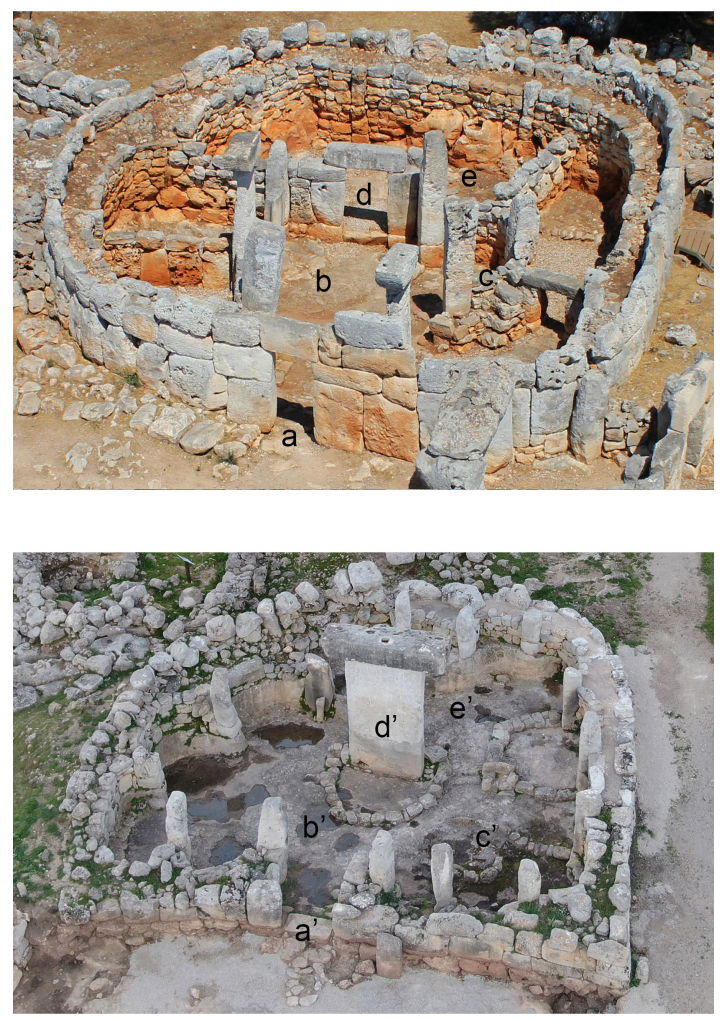

Figura 2. Arriba. vista general de una casa de planta circular (casa Cartailhac, Torre d'en Galmés. Fotografia. CIMe-Aeroview.es). a) acceso, b) patio central, c) estructura de combustión, d) acceso a la habitación norte, e) habitación norte. Abajo. vista general de un recinto de taula (Torralba d'en Salort). a') acceso, b') espacio ante la taula, c') estructura de combustión, d') taula, e') espacio tras la taula.

\section{Los recintos de taula: aspectos generales}

En el contexto del Talayótico Final, a partir del siglo VI a.C., se documenta la aparición de unos nuevos espacios monumentales y exclusivos de la isla de Menorca, llamados recintos de taula (e.g. Fernández-Miranda 2009). Se trata de un tipo de edificio muy bien definido, que se construye mediante la utilización de la técnica ciclópea. En prácticamente todos los casos se trata de construcciones con planta en forma de herradura, con un elemento central en forma de "T", formado por dos grandes losas superpuestas. En los ejemplos más monumentales, este elemento presenta una altura total que puede sobrepasar los cinco metros (Plantalamor 1991) (Figs. 2 y 3).
En el contexto del poblado, dichos recintos ocupan un espacio central, muy cercano a los talayots principales del asentamiento. Mientras que el número de talayots en un poblado varía, solamente se documenta un recinto de taula por poblado. La única excepción la constituye el yacimiento de So na Caçana, en donde se hallaron dos (Plantalamor 1987), aunque en este caso no se puede afirmar con certeza que ambos edificios estuvieran en uso de forma simultánea.

Hasta el momento se han documentado con seguridad 32 edificios que responden a esta tipología, pero es posible que existan restos de algunos más, todavía no localizados. Pese a todo, la monumentalidad de tales construcciones permite suponer que futuras prospecciones no incrementarán de forma significativa su número total. De los ejemplares conocidos, tan solo seis conservan en su posición original el característico elemento central, conocido como taula.

En cuanto a la planta, se trata de edificios delimitados por un muro perimetral ciclópeo de doble paramento dispuesto en forma de herradura, no siempre de forma simétrica. Esta herradura se cierra mediante una fachada recta o ligeramente cóncava, en el centro de la cual se dispone la entrada al espacio interior, flanqueada generalmente por dos grandes losas a modo de jambas, y presentando umbral y dintel, en muchas ocasiones desaparecido. En algunos casos, para acceder al interior es necesario subir uno o dos escalones. Es habitual que, en los edificios que se construyeron en una zona con desnivel, se rebajara algunos centímetros el sustrato rocoso, con el objetivo de nivelar el suelo.

El paramento externo del muro perimetral se construye a base de grandes bloques dispuestos de forma horizontal, como ocurre en Torralba d'en Salort, o bien mediante grandes losas dispuestas de forma vertical, como ocurre en la fachada del recinto de taula de Son Catlar. El paramento interno del muro perimetral se construye mediante bloques de dimensiones más pequeñas, formando hiladas irregulares. En algunos casos excepcionales, como el de Torre d'en Galmés, este paramento interno está construido con grandes losas colocadas verticalmente. En cualquier caso, esta cara interna del muro se divide en tramos, delimitados por pilastras adosadas al paramento o integradas en él, cuyo número varía dependiendo de la magnitud del edificio.

Dichas pilastras tendrían una función únicamente simbólica, a no ser que se acepte la hipótesis de que se trataba de recintos cubiertos. En ese caso podrían servir de apoyo para las 
vigas de madera que hipotéticamente cubrirían el recinto, utilizando la misma solución arquitectónica que la que se emplea en las bien documentadas casas de planta circular del mismo período (Pons 2016). Cabe señalar que se han planteado dos hipótesis respecto a la cubierta

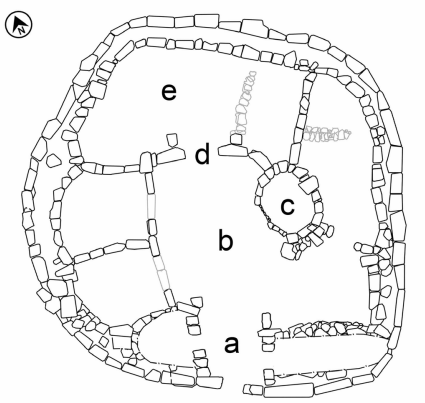

I

(4)

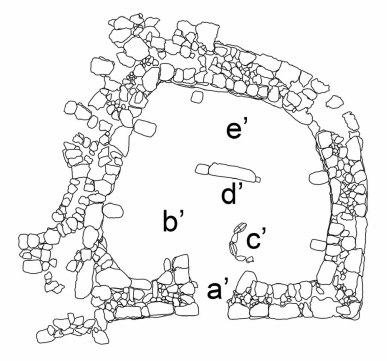

III

(A)

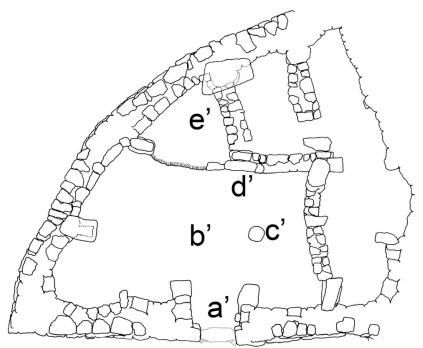

$\mathrm{V}$ de estos edificios: mientras que algunos investigadores proponen que se trataría de recintos a cielo abierto (Murray 1938; Fernández-Miranda 2009), otros no descartan la posibilidad de la existencia de techumbres totales o parciales (Cartailhac 1892; Plantalamor 1991).

(4)

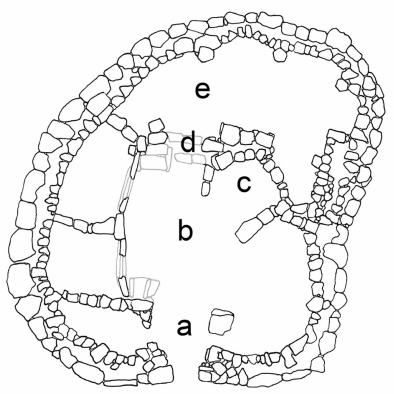

II

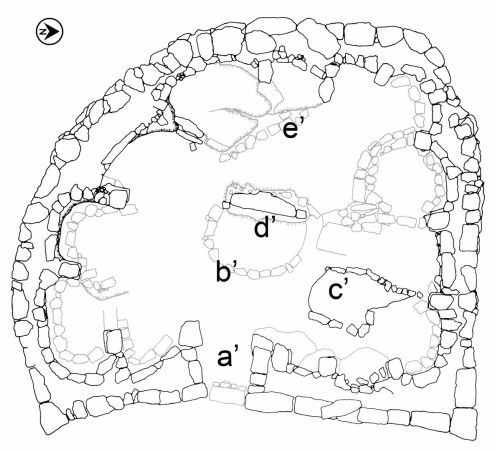

IV

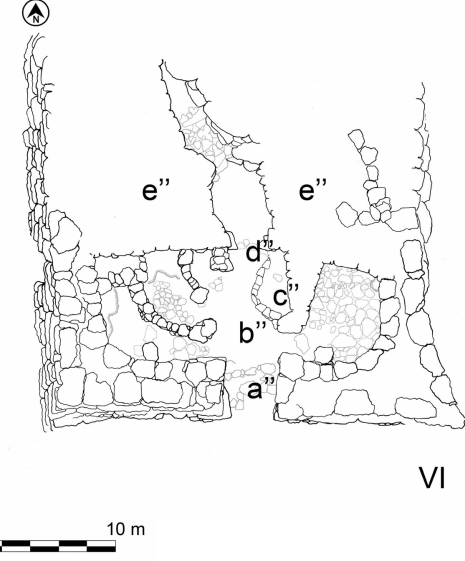

Figura 3. Planimetrías. I. Casa Cartailhac de Torre d'en Galmés (autora. Elena Sintes, Patrimoni Arqueològic i Cultural S.L.- M. Polo - IPCE). II. Casa del aeropuerto, Biniparratxet (reelaborado a partir de De Nicolás

1995). En las planimetrías I y II: a) acceso, b) patio central, c) estructura de combustión, d) acceso a la habitación norte, e) habitación norte. III. recinto de taula de Sa Cudia Cremada (elaboración propia). IV. recinto de taula de Torralba d'en Salort (reelaborado a partir de Fernández-Miranda 2009). V. recinto de taula (Monumento 5) de So na Caçana (reelaborado a partir de Plantalamor 1991). En las planimetrías III, IV y V: a') acceso, b') espacio ante la taula, c') estructura de combustión, d') taula, e') espacio tras la taula. VI. Edificio Sur de Cornia Nou (reelaborado a partir de Anglada et al. 2012). a') acceso, b') pasillo, c') estructura de combustión, d') acceso al pasillo del ámbito norte, e') partes macizas del ámbito norte. 
La distribución interna es aparentemente bastante simple. A grandes rasgos, es posible diferenciar dos espacios, uno relativamente rectangular, que se enmarca entre la fachada y la taula, y un segundo de forma semicircular, entre la misma taula y el ábside del edificio, el suelo del cual suele estar menos trabajado, siendo en ocasiones muy irregular (Fig. 2, abajo, espacios b' y e'; fig. 3, plantas III, IV y V, espacios b' y e'). Ambas zonas presentan características diferentes y existe la posibilidad de que la separación física fuera mayor en su momento, mediante la utilización de elementos perecederos. Esta diferenciación podría responder a la funcionalidad de los espacios, siendo la parte anterior una zona de ámbito público, y la zona posterior un área con carácter restringido.

Puntualmente se aprecian algunas soluciones de compartimentación interna como en el caso de Binissafullet o en el Monumento 5 de So na Caçana (Fig. 3, planta V), en donde existen muros internos que forman pequeñas estancias, ante la taula y por detrás de ella (Plantalamor 1987). En el caso de Torralba d'en Salort, se observan diversos lóbulos que conforman diferentes microespacios, construidos a partir del paramento interno del muro perimetral y separados entre sí por las pilastras antes mencionadas (Fig. 2, abajo y Fig. 3, planta IV).

De todas formas, el elemento que define y da nombre a este tipo de santuarios es la taula. La taula (término que significa mesa en catalán) es la estructura que se sitúa en el eje de la entrada al recinto, en posición central, aunque algo desplazada hacia el ábside (Fig. 3, plantas III, IV y V, elemento d'). Se trata de una gran losa monolítica encajada de forma vertical en un agujero practicado en el sustrato rocoso o que descansa sobre él, en la parte superior de la cual se emplaza otra losa en horizontal a modo de capitel, todo ello resultando en una forma de T. En algunos casos se conservan in situ dos pequeños bloques rectangulares que se sitúan flanqueando la base de la losa vertical.

Existen otros elementos de menor entidad que se documentan en mayor o menor medida en los recintos de taula, como por ejemplo nichos, columnas exentas o círculos de piedras correspondientes a la delimitación de estructuras de combustión.

\section{Comparativa entre los recintos de taula y las casas de planta circular}

\subsection{Aspectos cualitativos}

El elemento central de los recintos de taula ha sido analizado básicamente, en estudios ante- riores, a partir de su interpretación como una estructura arquitectónica de soporte, de carácter funcional (Cartailhac 1892) o bien como un elemento estrictamente simbólico. Así, para Murray (1934) el bloque superior de la taula sería la representación de una divinidad, mientras que la losa vertical serviría básicamente para sostener dicha representación en un lugar elevado y visible. Otros investigadores han aventurado que la taula, en conjunto, sería una representación esquemática de una figura humana (Lilliu y Schubart 1967) o de una cabeza bovina (Mascaró 1969). Cabe destacar que una gran parte de los intentos de identificar el concepto o entidad que se esconde tras las taulas se han centrado en esta estructura, obviando el recinto en el que se integra.

Un hecho que solo recientemente ha sido destacado por algunos autores son las similitudes existentes entre la arquitectura de los recintos de taula y la de las casas de planta circular (Sintes y Isbert 2009; Smith y Van Dommelen 2018), aunque desde una perspectiva diferente a la planteada en este trabajo y comparando la taula con algunas de las columnas que flanquean el patio central de las casas.

\subsubsection{Las casas de planta circular}

Estas estructuras se documentan, al igual que los recintos de taula, a partir del siglo VI a.C. (Torres 2017). Pese a su nombre, presentan en realidad plantas de formas diversas. Mientras que algunas son ciertamente de tendencia circular, otras son más irregulares, adaptándose a la topografía del terreno o adosándose a otras casas preexistentes. En otros casos la puerta de entrada se abre en el centro de una fachada más bien plana.

En lo que respecta a la técnica constructiva, en el muro perimetral se observa siempre una técnica ciclópea de doble paramento. En la cara externa existe una primera hilada de pequeños bloques dispuestos de forma horizontal, que tienen como función nivelar el terreno y servir de base para una hilada de grandes losas verticales, de unos $100 \mathrm{~cm}$ de altura. En otros casos, menos frecuentes, se observan grandes bloques dispuestos de forma horizontal, formando hiladas irregulares. En ambos casos se dispone, por encima de estas primeras hiladas, un aparejo de menores dimensiones, normalmente mal conservado. En la cara que mira al interior de la casa, el paramento está formado generalmente por piedras de dimensiones medianas $(30-50 \mathrm{~cm})$ dispuestas ho- 
rizontalmente y formando hiladas irregulares. El relleno interno del muro se compone de piedras de pequeñas dimensiones y tierra arcillosa. Los muros internos de compartimentación, habitualmente de paramento simple, son perpendiculares al muro perimetral de la casa. Por ese lado, se adosan generalmente a unas pilastras polilíticas integradas en dicho muro perimetral o adosadas a él (Fig. 3, plantas I y II). Por el otro extremo, se adosan a las grandes columnas monolíticas que flanquean el patio central. Dichas pilastras y columnas constituían los elementos de soporte de las vigas de madera del techo.

El material constructivo básico de este tipo de viviendas son las calcarenitas miocénicas duras, extraídas del entorno inmediato de la estructura (Pérez-Juez y Goldberg 2018).

Estas estructuras presentan generalmente un diámetro máximo de entre 12 y 14 metros, y su distribución muestra una gran estandarización. A partir de la entrada se accede a un breve pasi1lo, que da acceso a un patio central. Dispuestas de forma radial, alrededor del patio, se sitúan las diferentes habitaciones, cuyo número oscila generalmente entre cinco y siete. En el extremo norte se ubica siempre la habitación de mayores dimensiones (Fig. 3, plantas I y II, espacio e). $\mathrm{Su}$ acceso (Fig. 3, plantas I y II, espacio d) desde el patio central (Fig. 3, plantas I y II, espacio b) presenta un carácter más monumental que el de las otras estancias y, por otro lado, constituye la puerta más visible cuando se penetra en la vivienda a través de la puerta principal, pues está alineada con el breve pasillo que se abre a continuación del acceso (Fig. 3, plantas I y II, espacio a). El suelo de esta habitación suele estar ligeramente elevado respecto al resto de la casa. La estructura de combustión se ubica siempre en el patio, al lado derecho del acceso al mencionado ámbito norte (Fig. 3, plantas I y II, espacio c).

\subsubsection{Aspectos arquitectónicos comunes a ambos tipos de estructuras}

La técnica constructiva de los recintos de taula y las casas de planta circular tiene muchos puntos en común, caracterizándose normalmente, en ambos casos, por la existencia de un muro perimetral de doble paramento, con grandes bloques en la cara externa y piedras menores en la cara interna. Aun así, el aparejo de la cara interna del muro perimetral de los recintos de taula es, generalmente, de mayores dimensiones que el de las casas.
Una de las similitudes más destacables entre las casas de planta circular y los recintos de taula es la existencia de pilastras en la cara interna del muro perimetral, que contribuyen a la ordenación del espacio interno del edificio. En el caso de las viviendas, como ya se ha expuesto, dichas pilastras sirven de punto de partida de los muros de compartimentación, si bien en el ámbito norte aparecen habitualmente como elementos independientes de dichos tabiques (Fig. 3, planta II, espacio e). En los recintos de taula, generalmente, estos elementos simplemente insinúan una división del espacio interno, si bien es cierto que en algunos recintos como el de Torralba d'en Salort, tal y como se ha expuesto en el apartado anterior, sobresalen del muro lo suficiente como para generar una serie de lóbulos claramente diferenciados, en número similar a las habitaciones de las casas (Fig. 3, planta IV).

La taula propiamente dicha ocupa, dentro de su recinto, una posición ligeramente excéntrica, más cerca del ábside que de la fachada, y alineada generalmente con la puerta de acceso al recinto (Fig. 3, plantas III, IV y V, elemento d'). Dicha posición es comparable a la que ocupa la entrada del ámbito norte en las casas de planta circular (Fig. 3, plantas I y II, espacio d). Al igual que ocurre en algunos casos con la habitación norte de las casas, el suelo del espacio situado detrás de la taula se encuentra con frecuencia a una cota ligeramente superior a la del resto del edificio. La ubicación de la estructura de combustión en casas de planta circular y recintos de taula es análoga si se toma en consideración la identificación entre la entrada de la habitación norte y la taula. En ambos casos, la estructura de combustión se sitúa delante y a la derecha de los elementos considerados (puerta y taula, respectivamente) (Fig. 3, plantas I, II, III y IV, espacios c y c') y está delimitada con molinos manuales ya amortizados. El hecho de no hallar ningún elemento ante la taula cobra sentido si ésta se interpreta como un acceso simbólico. En este sentido, es necesario destacar que el semicírculo de piedras que aparece ante la taula de Torralba d'en Salort (Fig. 3, planta IV) está asociada a una reutilización del espacio en época romana (Fernández-Miranda 2009) y no se documenta en ningún otro recinto.

Por otro lado, existe una característica compartida a todas las taulas y que no encaja con la interpretación de esta construcción como un simple elemento de soporte ni como la representación de una efigie animal o una figura humana. Se trata del escaso grosor de 
la piedra soporte, que en algunos casos no excede de los $40 \mathrm{~cm}$. La delgadez de esta parte de la taula contrasta con su anchura y su altura, pero también con las dimensiones de la piedra superior, que en todos los casos sobresale no solo por los lados, sino también por la parte anterior y posterior de la piedra soporte (Fig. 4).

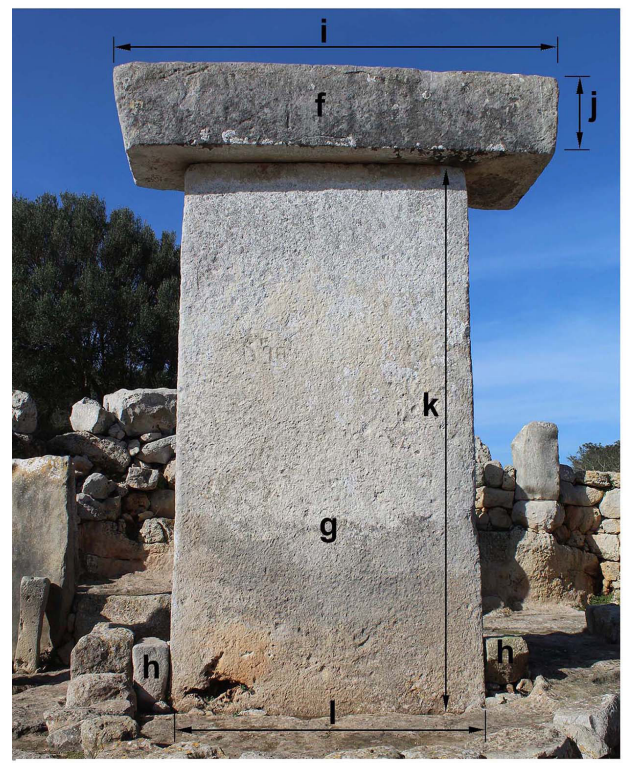

Taula de Torralba d'en Salort.

f) capitel, g) losa vertical, h) bloques laterales, i) ancho capitel, j) alto capitel, k) alto losa vertical, I) ancho losa vertical

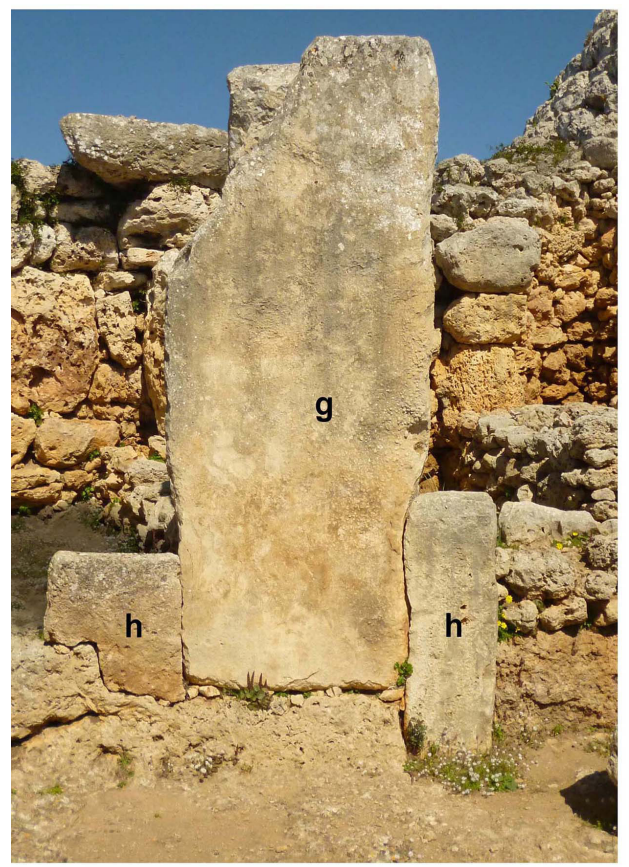

Taula de So na Caçana (Monumento 5). g) losa vertical, h) bloques laterales

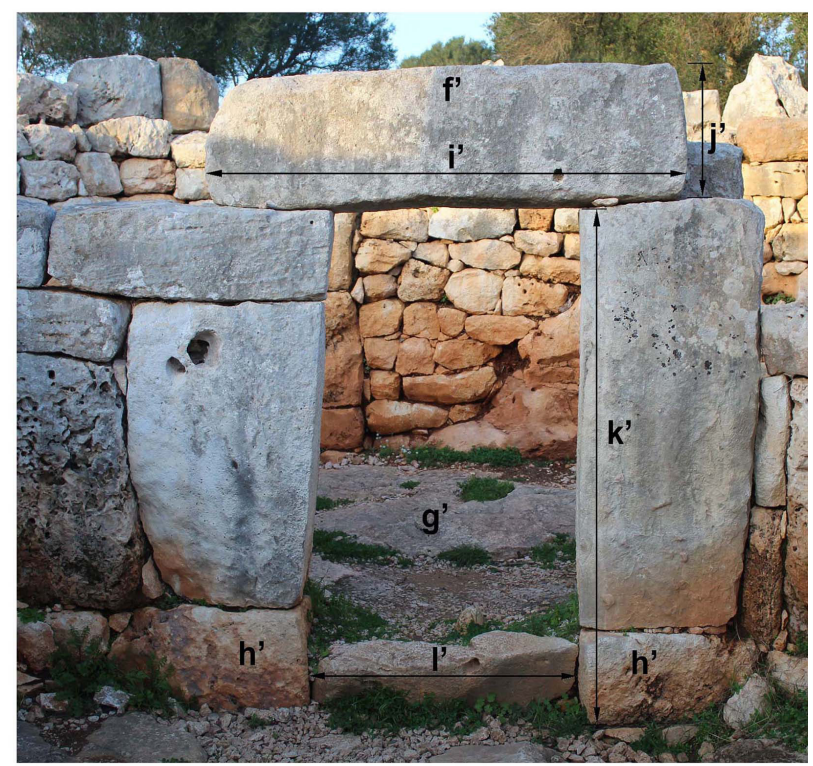

Entrada a la habitación norte del círculo Cartailhac de Torre d'en Galmés.

f') dintel, g') acceso, h') soportes de las jambas,

i') ancho dintel, j') alto dintel, k') alto acceso,

l') ancho acceso

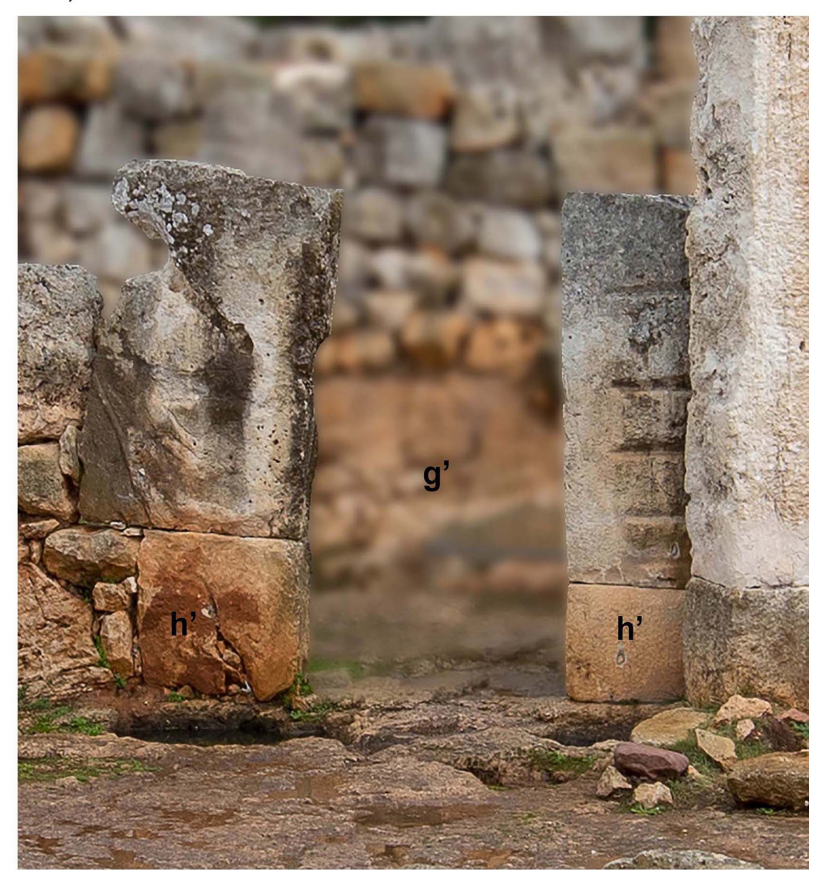

Entrada a la habitación norte del círculo 6 de Torre d'en Galmés.

g') acceso, h') soportes de las jambas

Figura 4. Ejemplos de taulas y accesos con sus elementos constitutivos y la indicación de las variables utilizadas en el análisis estadístico. 
Otro elemento que cobra sentido a la luz de la analogía entre taulas y puertas son los dos bloques de piedra que aparecen flanqueando la taula en algunos recintos. La ubicación y proporciones de dichos elementos son parecidas a las de los dos bloques de piedra que sirven de soporte a las jambas de las puertas que dan acceso al ámbito norte de las casas de planta circular (Fig. 4).

Aparentemente, por tanto, existe una concepción del espacio compartida en ambos tipos de edificios, que permite la creación de un paralelismo entre el ámbito religioso y el ámbito doméstico.

\subsubsection{El Edificio Sur de Cornia Nou}

Un antecedente del esquema constructivo descrito en el apartado anterior parece observarse en un edificio correspondiente al periodo Talayótico Inicial. Se trata del Edificio Sur de Cornia Nou, sobre el cual se había propuesto ya, anteriormente, que podría tratarse de un precursor arquitectónico de los recintos de taula (Anglada et al. 2013). Aunque hasta el momento no se ha excavado ningún otro edificio equivalente, estructuras parecidas se documentan en otros asentamientos, como por ejemplo el de Santa Mónica (Plantalamor 1991). Las intervenciones arqueológicas desarrolladas en el Edificio Sur permitieron documentar un tipo de estructura ciclópea de carácter no doméstico desconocida hasta entonces, donde se desarrollaron actividades de procesado de cereales, de forma comunitaria. También pudieron recuperarse gran cantidad de restos de fauna doméstica, especialmente caprinos domésticos (Anglada et al. 2012). No obstante, algunas características del edificio han permitido proponer que algunas de las actividades desarrolladas en el interior del edificio podrían haber tenido un componente ritual y simbólico (Hochsieder 2015).

El Edificio Sur presenta algunos rasgos en común con los recintos de taula, tales como sus dimensiones o la fachada ligeramente cóncava con el acceso situado en posición central (Fig. 3, planta VI). El material edilicio, al igual que en las casas de planta circular y los recintos de taula, son los bloques de calcarenita miocénica dura. En lo que respecta a la técnica constructiva de este edificio, destaca la utilización, en la base de la fachada, de grandes bloques de piedra, algunos de ellos dispuestos de forma vertical. La mitad superior, en cambio, está formada por hiladas de piedras de menores dimensiones, escasamente desbastadas y colocadas horizontalmente. La cara interna del muro no presenta los bloques de gran tamaño que se observan en la cara externa, si no que está construida a base de piedras de dimensiones medianas $(30-50 \mathrm{~cm})$ formando hiladas irregulares. En la cara interior del mismo muro se observan pilastras polilíticas, a ambos lados de la puerta de acceso. Todos estos rasgos arquitectónicos aparecen también en los recintos de taula.

Pese a todo, existen importantes diferencias entre los recintos de taula y el Edificio Sur de Cornia Nou. En el primer caso, como se ha visto, se trata de espacios escasamente compartimentados, mientras que el Edifico Sur presenta una estructura interna transversalmente dividida en dos ámbitos. El primero de estos dos ámbitos, más cercano a la entrada, se ordena a partir de un pasillo central, con una habitación a cada lado. El segundo ámbito también presenta un pasillo central, pero los espacios laterales son totalmente macizos y, en consecuencia, intransitables (Fig. 3, planta VI, espacio e"). El pasillo constituye solamente un acceso a la cubierta del edificio, desde la cual se puede acceder a la escalera monumental del talayot situado tras el edificio. Es interesante constatar que la puerta que separa los dos ámbitos ocupa una posición equivalente, en la planta del edificio, a la del elemento central de los recintos de taula: en posición central respecto al eje longitudinal del edificio, pero ligeramente desplazada hacia el fondo (Fig. 3, planta VI, espacio d"). La estructura de combustión documentada en el interior del Edificio Sur ocupa una posición análoga a la de los hogares de las casas de planta circular: ante la puerta que da acceso al ámbito situado al norte y a la derecha de ésta (Fig. 3, planta VI, espacio c"). Se trata de una ubicación que, como se ha expuesto, presenta paralelismos en los recintos de taula. El adosamiento o yuxtaposición a un talayot es también una característica que se observa en algunos recintos de taula, como el So na Caçana (Fig. 3, planta V) o el de Torre d'en Galmés, respectivamente. Por otro lado, cabe destacar que la estructura general del edificio presenta, a parte de la ya mencionada ubicación de la estructura de combustión, otros elementos en común con las casas de planta circular. Así, en el Edificio Sur se puede observar una ubicación de los espacios internos alrededor de un elemento central que actúa como distribuidor, si bien en este caso se trata de un espacio cubierto y en las casas de planta circular es un 
patio. Aun así, parece significativo que este espacio central esté flanqueado, en uno de sus lados, por columnas a las cuales se adosan muros de compartimentación internos de paramento simple (Fig. 3, planta VI) igual que ocurre en las casas de planta circular. También igual que en las casas, estos muros contienen con frecuencia molinos manuales amortizados y reutilizados como material constructivo. Las dataciones radiocarbónicas permiten situar el abandono del Edificio Sur de Cornia Nou en torno al 600 cal BC (Portillo et al. 2014), de forma que, cronológicamente, se sitúa cerca de la fecha propuesta de inicio de construcción de los recintos de taula (FernándezMiranda 2009) y las casas de planta circular (Torres 2017).

\subsubsection{Síntesis}

La hipótesis planteada en este trabajo, por tanto, se basa en la idea según la cual casas y recintos de taula son la plasmación de una misma concepción ideológica del espacio aplicada a la arquitectura, la cual podría hundir sus raíces en la etapa crono-cultural precedente. En este contexto, la taula sería la representación de una puerta en la que la relación hueco-volumen se encontraría parcialmente invertida. Así, la piedra superior representaría el dintel, mientras que la piedra soporte representaría el vano de la puerta. Se trataría, por tanto, de una puerta que no se sitúa en ningún muro, si no que aparece como un elemento aislado. Pese a constituir un sistema de representación en cierto modo bastante abstracto, se conocen otros ejemplos de contextos culturales diferentes, en los que las puertas simbólicas aparecen desvinculadas de cualquier muro, como es el caso de las estelas de falsa-puerta egipcias (Kanawati 1987; Vivas 2019). Cabe destacar, por otro lado, que existen algunos casos en que la taula parece haber estado integrada en un muro transversal, como en el monumento 5 de So na Caçana (Fig. 3, planta V). En otros casos, como en los recintos de taula de Son Catlar o Trepucó, parece existir al menos un elemento de cierre, de escasa altura, en el cual se integra la taula. Estos casos podrían interpretarse como estadios más iniciales de un proceso de creciente abstracción.

\subsection{Análisis de similitud entre taulas y puertas}

El estudio del fenómeno arqueológico conceptualizado en este artículo también puede ser abordado mediante técnicas analíticas in- ferenciales y análisis cuantitativos. De hecho, si las taulas son representaciones simbólicas y monumentales de puertas, tal y como se teoriza, ambas estructuras deberían presentar las mismas proporciones arquitectónicas y una relación similar en el conjunto y disposición de sus componentes. Estos factores son parametrizables, medibles y contrastables estadísticamente justificando el uso de dicha ciencia matemática para su estudio.

\subsubsection{Metodología}

A partir de la pregunta $¿$ son las taulas arquitectónicamente similares a las puertas de los hábitats talayóticos? se plantearon dos hipótesis estadísticas que a continuación son verificadas mediante el diseño de un experimento y el desarrollo de un análisis de similitud entre dos muestras.

- Hipótesis nula $\left(\mathrm{H}_{0}\right)$ : taulas y puertas son arquitectónicamente similares.

- Hipótesis alternativa $\left(\mathrm{H}_{1}\right)$ : taulas y puertas son arquitectónicamente distintas.

Los análisis estadísticos para el contraste inferencial de las hipótesis se han ejecutado con el entorno y el lenguaje de programación $\mathrm{R}$ por su especificidad, robustez y licencia GPL. Para facilitar los cálculos y la representación gráfica de los resultados se utilizó la interface R Commander y RStudio.

\subsubsection{Descripción de la muestra y selección de las variables}

\section{a. Estrategia de muestreo y diseño experimental}

Los monumentos centrales de los recintos de taula, como sujetos de estudio, son actualmente del orden de 32, según consta en el catálogo de patrimonio histórico de Menorca. No obstante, en dicho inventario únicamente se recogen aquellas estructuras que han resistido al paso del tiempo, provocando que el registro esté incompleto. A su vez, las taulas documentadas no presentan ni el mismo grado de conservación ni estados de estudio similares. Consecuentemente la población disponible para el análisis estadístico está sesgada afectando directamente al tamaño muestral y a la aleatoriedad de la selección. 
Para minimizar los errores que pudieran derivarse de individuos incompletos, se ha descartado la aleatoriedad, seleccionando únicamente aquellas taulas que presentan la mejor conservación estructural del monumento central y la menor degradación o alteración moderna de sus componentes. En este sentido, aparte de incluir en el estudio las taulas intactas también se han tenido en cuenta aquellas que conservan la morfología original de su capitel y losa vertical, aunque estos estén desarticulados o desplazados.

Revisado el catálogo de patrimonio histórico de Menorca y visitadas las taulas conservadas, la muestra se configuró con nueve individuos: Binisafullet, Cotaina, Sa Torreta de Tramuntana, Talatí de Dalt, Torralba d'en Salort, Torre d'en Galmés, Torrellisar Vell, Torretrencada, Trepucó (Fig.1). Para comprobar si existen diferencias de esta muestra con respecto a las puertas de hábitats talayóticos se configuró un segundo conjunto de observaciones.

Para determinar el tamaño muestral necesario mínimo de la segunda muestra y con el objetivo de que el estudio tuviera la solidez estadística suficiente para confirmar la hipótesis, se desarrolló un diseño experimental. Los parámetros de control asignados al análisis de potencia estadística de la experimentación se encaminaban a un posterior test de similitud o Hotelling con un tamaño de 9 observaciones para una de las dos muestras, un nivel de significación de $0,05 \mathrm{y}$ un tamaño de efecto grande de 0,8 . En cuanto a la potencia, esta fue de un valor bajo de 0,35 , conscientes que se estaba cometiendo un error de tipo II ya que la selección de las observaciones no había sido aleatoria. En base a los parámetros establecidos, el resultado obtenido para el contraste de muestras requiere que en la segunda se analicen un mínimo de 9 individuos.

Las observaciones disponibles para las puertas eran igualmente escasas, con un grado de conservación menor al de las taulas y frecuentes restauraciones modernas. Aún en estos casos, se han considerado las dimensiones como válidas ya que el proceso de reconstrucción de la estructura fue mediante la técnica de la anastilosis, utilizando los bloques originales (jambas y dintel) de acuerdo con lo que establece la ley 12/1998 de Patrimonio Histórico de las Islas Baleares. En este caso, la muestra pudo contar con diez individuos procedentes de distintos poblados como Torre d'en Galmés (puerta principal y puerta de la pequeña habi- tación izquierda del Círculo 7 (Ferrer y Riudavets 2015); puerta de la casa, puerta del ámbito norte, puertecilla 1 y puertecilla 2 del círculo de Cartailhac (Sintes y Isbert 2009); puerta principal y puerta interior del Edificio Sur de Cornia Nou (Anglada et al. 2012) y puertas de los espacios 1 y 2 del poblado de Talatí de Dalt (Juan y Pons 2005) (Fig. 1). La diversidad de yacimientos garantizó una mayor variabilidad de las observaciones.

\section{b. Las variables}

Las variables contempladas en este estudio analítico han sido de carácter cuantitativo y comunes a ambos conjuntos muestrales. Para ello, las estructuras han sido conceptualmente descompuestas permitiendo describirlas de manera uniforme (Barceló 1988). Las observaciones han sido homogéneas, focalizadas en aquellos elementos reiterativos de cada conjunto. Se han descartado los atributos de carácter singular, exclusivo de algunos yacimientos, o que presentaban una mayor variabilidad arquitectónica (piedras laterales, umbral, etc.). Los componentes morfológicos seleccionados y medidos han permitido establecer relaciones de similitud entre las dos muestras.

Siguiendo los preceptos propuestos por la descripción arquitectónica tradicional en el plano frontal (Ching 2014), taulas y puertas se han descompuesto respectivamente en dos componentes. Las taulas comprenden la losa vertical o pie, entendiendo este como el elemento en contacto con el suelo que está en posición vertical (Fig. 4, elemento g) y el capitel, siendo este el elemento en posición horizontal que corona la estructura y sobrepasa el soporte (Fig. 4, elemento f). A su vez, las puertas de los hábitats talayóticos se componen del acceso, entendiendo este como el espacio abierto en la pared para poder cruzar (Fig. 4, elemento g'), y el dintel, siendo este la pieza horizontal situada en la parte superior de las puertas destinada a soportar la carga del muro (Fig. 4, elemento f').

De tratarse las taulas de representaciones simbólicas y monumentales de puertas como se presupone, los rasgos arquitectónicos comunes y equivalentes entre ambas deberían ser el dintel por el capitel y el acceso por la losa vertical. De hecho, los citados componentes presentan las mismas morfologías en ambas muestras garantizando un correcto análisis de similitud. Incluso el espacio vacío de las puer- 
tas (acceso) es similar pero complementaria o negativamente opuesto a las losas verticales de las taulas. Por consecuente, las variables medidas, y que a su vez explican la variabilidad observada entre los individuos de cada muestra, son para las taulas: el ancho y alto de la losa vertical y el ancho y alto del capitel; y para las puertas: el ancho y alto del acceso y el ancho y alto del dintel (Tab. 1 y 2, fig. 4).

Tabla 1. Conjunto de puertas analizadas con sus respectivas variables

\begin{tabular}{|c|c|c|c|c|}
\hline & $\begin{array}{l}\text { ANCHO DEL } \\
\text { ACCESO }(\mathrm{cm})\end{array}$ & $\begin{array}{r}\text { ALTO DEL } \\
\text { ACCESO }(\mathrm{cm})\end{array}$ & $\begin{array}{l}\text { ANCHO DEL } \\
\text { DINTEL }(\mathrm{cm})\end{array}$ & $\begin{array}{r}\text { ALTO DEL } \\
\text { DINTEL }(\mathrm{cm})\end{array}$ \\
\hline $\begin{array}{l}\text { TORRE D'EN GALMÉS C7 } \\
\text { (PUERTA PRINCIPAL) }\end{array}$ & 100 & 188 & 170 & 53 \\
\hline $\begin{array}{l}\text { TORRE D'EN GALMÉS C7 } \\
\text { (PUERTA PEQUEÑA) }\end{array}$ & 61 & 99 & 95 & 30 \\
\hline $\begin{array}{l}\text { TORRE D'EN GALMÉS CC } \\
\text { (PUERTA CASA) }\end{array}$ & 92 & 192 & 117 & 59 \\
\hline $\begin{array}{l}\text { TORRE D'EN GALMÉS CC } \\
\text { (PUERTA AMBITO N) }\end{array}$ & 111 & 173 & 189 & 50 \\
\hline $\begin{array}{l}\text { TORRE D'EN GALMÉS CC } \\
\text { (PUERTECILLA 1) }\end{array}$ & 56 & 92 & 107 & 22 \\
\hline $\begin{array}{l}\text { TORRE D'EN GALMÉS CC } \\
\text { (PUERTECILLA 2) } \\
\end{array}$ & 70 & 87 & 95 & 23 \\
\hline $\begin{array}{l}\text { CORNIA NOU } \\
\text { (PUERTA PRINCIPAL) }\end{array}$ & 121 & 175 & 160 & 65 \\
\hline $\begin{array}{l}\text { CORNIA NOU } \\
\text { (PUERTA INTERIOR) }\end{array}$ & 100 & 176 & 130 & 51 \\
\hline $\begin{array}{l}\text { TALATÍ DE DALT C } \\
\text { (PUERTA 1) }\end{array}$ & 84 & 110 & 140 & 52 \\
\hline $\begin{array}{l}\text { TALATÍ DE DALT C } \\
\text { (PUERTA 2) }\end{array}$ & 70 & 125 & 167 & 61 \\
\hline
\end{tabular}

Tabla 2. Conjunto de taulas analizadas con sus respectivas variables

\begin{tabular}{|c|c|c|c|c|}
\hline & $\begin{array}{r}\text { ANCHO } \\
\text { DE LA L. } \\
\text { VERTICAL } \\
(\mathrm{cm}) \\
\end{array}$ & $\begin{array}{r}\text { ALTO } \\
\text { DE LA L. } \\
\text { VERTICAL } \\
(\mathrm{cm}) \\
\end{array}$ & $\begin{array}{r}\text { ANCHO } \\
\text { DEL } \\
\text { CAPITEL } \\
(\mathrm{cm}) \\
\end{array}$ & $\begin{array}{r}\text { ALTO } \\
\text { DEL } \\
\text { CAPITEL } \\
\text { (cm) } \\
\end{array}$ \\
\hline BINISSAFULLET & 116 & 303 & 195 & 47 \\
\hline COTAINA & 129 & 218 & 195 & 47 \\
\hline SA T. DE TRAMUNTANA & 185 & 370 & 275 & 60 \\
\hline TALATÍ DE DALT & 260 & 300 & 400 & 38 \\
\hline TORRALBA D'EN SALORT & 250 & 430 & 380 & 70 \\
\hline TORRE D'EN GALMÉS & 160 & 195 & 250 & 65 \\
\hline TORRELLISAR & 164 & 260 & 345 & 50 \\
\hline TORRETRENCADA & 195 & 275 & 310 & 45 \\
\hline TREPUCÓ & 275 & 420 & 365 & 60 \\
\hline
\end{tabular}

Para garantizar una correcta medición de cada uno de los componentes de las observaciones, se aceptó el ideal de la forma geométrica básica que representaban dejando de lado sus irregularidades. Debido a la diversidad de medidas que proporcionan los distintos autores en la bibliografía (Hochsieder y Knösel 1995; Plantalamor 1991; Mascaró 1969), se optó por tomar los datos nuevamente in situ mediante la medición directa de los componentes.

\subsubsection{Análisis de la similitud}

\section{a. Análisis de regresión múltiple y de cova- rianza}

La diferencia de magnitudes entre taulas y puertas impide una comparación directa del comportamiento de los valores de cada una de las variables, por lo que es necesario que estas sean combinadas para generar índices de relación homólogos entre las dos muestras. Para ello, previo al test de Hotelling, se realizó un análisis de regresión para cada muestra con el objetivo de valorar la existencia de correlaciones entre sus variables. Posteriormente, se ejecutó un análisis de covarianza (ANCOVA) para comparar si las tendencias de las líneas de regresión obtenidas eran similares entre taulas y puertas permitiendo hacer una primera aproximación a su similitud.

Los análisis de regresión múltiple llevados a cabo han confrontado el ancho del acceso, para las puertas, y el ancho de la losa vertical, para las taulas (variables dependientes) a las demás variables contempladas en las respectivas muestras (variables independientes). El resultado obtenido en ambos casos fue de valores p significativos (p-valor puertas: 0,02589, p-valor taulas: 0,01341). Se confirma, a nivel estadístico que, en ambas muestras, las variables están correlacionadas linealmente, pero el nivel de significación de los resultados indica que algunas variables tienen una relación de menor fuerza o no influyen.

El análisis de los coeficientes de correlación obtenidos en ambas muestras evidencia que mayormente las relaciones lineales son positivas y muy fuertes a excepción de la variable "alto del capitel" en el grupo de las taulas (Fig. 5 y Fig. 6) pudiendo ser descartada en el estudio. En cualquier caso, las correlaciones detectadas entre las variables de cada componente permiten asegurar la existencia de relaciones de proporción. A su vez, dichas correlaciones no se reducen exclusivamente a las variables que configuran cada componente, sino que también se dan con la combinación de estos, permitiendo asegurar que el acceso y el dintel para las puertas, así como la losa vertical y el capitel para las taulas funcionan de forma orgánica como un todo. 


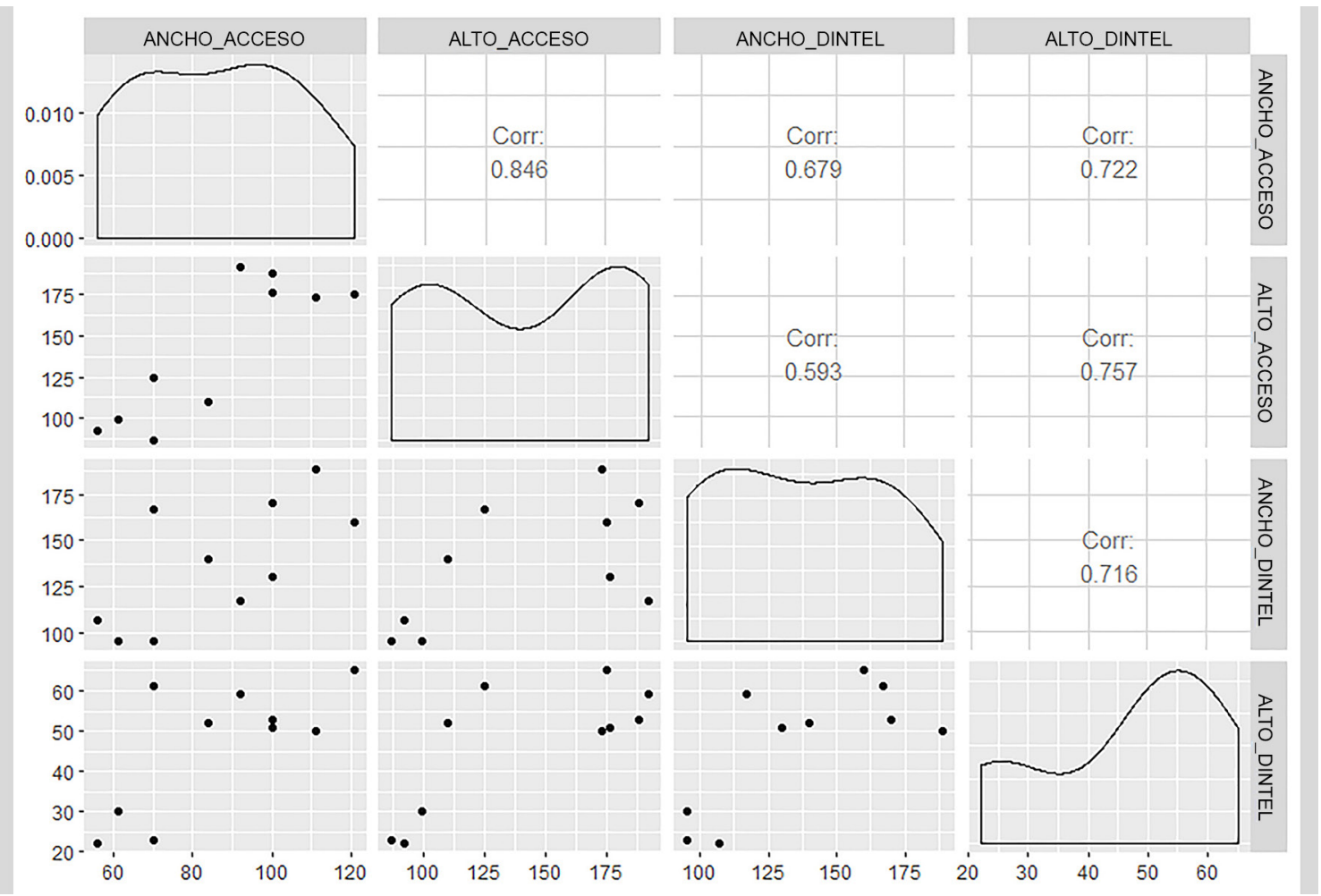

Figura 5. Diagrama de dispersión y de densidad enfrentando las variables de las puertas dos a dos con sus respectivos valores de correlación

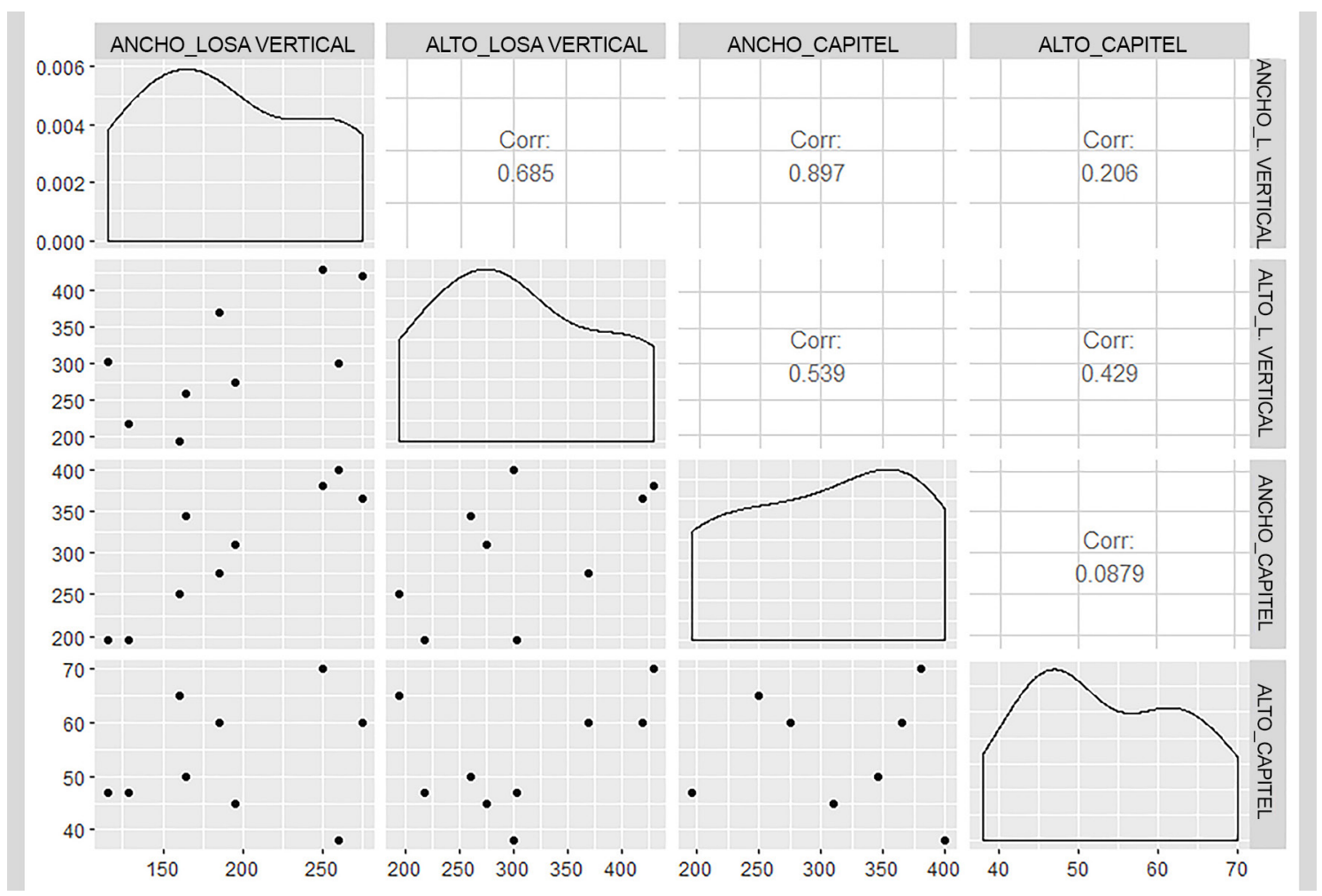

Figura 6. Diagrama de dispersión y de densidad enfrentando las variables de las taulas dos a dos con sus respectivos valores de correlación 
El análisis de covarianza ejecutado a posteriori se encaminó a estudiar la interacción de las variables categóricas con las variables independientes de ambas muestras simultáneamente para determinar si taulas y puertas presentaban comportamientos arquitectónicos similares. En cinco de las doce combinaciones posibles, las líneas de regresión entre taulas y puertas presentaban similitudes estadísticamente significativas a nivel de pendiente como de intercepto (Fig. 7). Este es el caso por ejemplo del alto del acceso y el ancho del dintel de las puertas que aumentan de la misma manera que lo hacen el alto de la losa vertical y el ancho del capitel de las taulas con relación al ancho del acceso y el de la losa vertical. Consecuentemente en estas combinaciones ambas muestras presentan los mismos principios arquitectónicos a nivel de proporciones y relación entre componentes.

En otras cuatro combinaciones de variables, el análisis de covarianza confirma que las líneas de regresión entre taulas y puertas son estadísticamente similares en relación con las pendientes, pero no en cuanto a los interceptos (Fig. 7). En estos casos, la diferencia entre los interceptos es producto de la diferencia de magnitud de los valores entre los factores de la variable categórica ya advertida y tomada en cuenta por la monumentalidad de las taulas respecto a las puertas. Dejando de lado el intercepto, la confirmación estadística de pendientes idénticas refuerza la hipótesis de similitud entre ambas muestras.
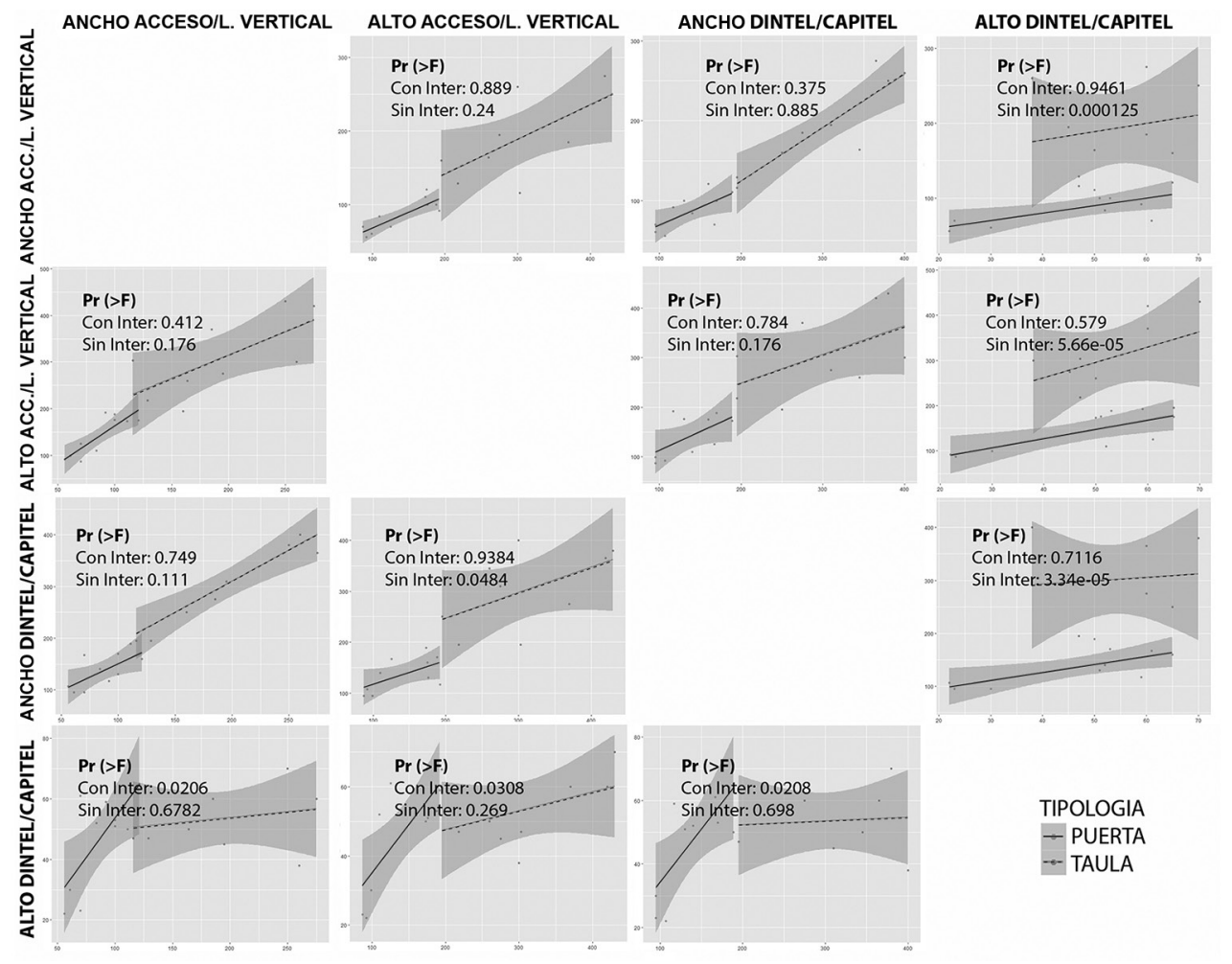

Figura 7. Regresiones lineales enfrentando todas las variables dos a dos sin separar por muestra y con sus respectivos coeficientes de interacción y sin interacción.

Finalmente, solo son negativas tres interacciones, precisamente aquellas que tienen como variable dependiente el alto del dintel o capitel. Este resultado puede ser explicado mediante la lectura funcional de dichos componentes. En el caso de las puertas el alto del dintel está fuertemente determinado por la magnitud de la carga que debe soportar. En cambio, en las taulas, el alto del capitel no está sujeto a dicha necesidad. Por lo tanto, el alto del dintel y del capitel no presentan comportamientos similares ya que en el plano frontal prevalece la funcionalidad a la lectura estética o simbológica.

\section{b. Test de Hotelling}

El test de Hotelling es una expansión del test $\mathrm{t}$ de Student que permite comparar las observaciones de 2 muestras que contienen más 
de dos variables. La diferencia de magnitudes advertida entre taulas y puertas impedía una comparación directa de las variables de las dos muestras. Por este motivo, y en base a regresiones lineales detectadas que confirman la existencia de relaciones de proporción de los componentes y funcionamiento orgánico entre componentes de una misma tipología de estructura, se han combinado las variables entre sí para cada muestra con el objetivo de generar índices homólogos entre los dos conjuntos de observaciones. Estos índices, a su vez, permiten superar la comparación de relaciones de proporción entre ambas tipologías, que ya se ha realizado indirectamente con el análisis de covarianza.

Las nuevas variables resultantes de la combinación de factores contemplados en cada muestra son del orden de seis si se descartan las repeticiones en las que se permutan los valores. A su vez, en este proceso, se han eliminado las combinaciones en las que intervinieran las variables originales de "alto del capitel" y "alto del dintel" por presentar regresiones lineales débiles y no tener interacciones. En este contexto se han obtenido un total de tres nuevas variables para cada muestra (Tab. 3).

Tabla 3. Taulas y puertas analizadas con las nuevas variables desarrolladas

\begin{tabular}{|c|c|c|c|c|}
\hline & TIPOLOGIA & \begin{tabular}{|r|} 
ANCHO DE LA L \\
VERTICAL \\
ACCESO / ALTO \\
DE LA L LERTICAL \\
OACCESO \\
\end{tabular} & \begin{tabular}{|r|} 
ANCHO DE LA L. \\
VERTICAL \\
ACCESO /ANCHO \\
DEL CAPITEL \\
DINTEL \\
\end{tabular} & \begin{tabular}{|r|r} 
ALTO DE LAL \\
VERTICAL \\
ACCESO / ANCHO \\
DEL CAPITEL \\
DINTE
\end{tabular} \\
\hline TORRE D'EN GALMÉS C7 (PUERTA PRINCIPAL) & PUERTA & 0,53 & 0,59 & 1,11 \\
\hline TORRE D'EN GALMÉS C7 (PUERTA PEQUEÑA) & PUERTA & 0,62 & 0,64 & 1,0 \\
\hline TORRE D'EN GALMÉS CC (PUERTA CASA) & PUERTA & 0,48 & 0,79 & 1,6 \\
\hline TORRE D'EN GALMÉS CC (PUERTA AMBITO N) & PUERTA & 0,64 & 0,59 & 0,92 \\
\hline TORRE D'EN GALMÉS CC (PUERTECILIA 1) & PUERTA & 0,61 & 0,52 & 0,86 \\
\hline TORRE D'EN GALMÉS CC (PUERTECILA 2) & PUERTA & 0,80 & 0,74 & 0,92 \\
\hline CORNIA NOU (PUERTA PRINCIPAL) & PUERTA & 0,69 & 0,76 & 1,05 \\
\hline CORNIA NOU (PUERTA INTERIOR) & PUERTA & 0,57 & 0,77 & 1,35 \\
\hline TALATÍ DE DALT C (PUERTA 1) & PUERTA & 0,76 & 0,60 & 0,79 \\
\hline TALATÍ DE DALT C (PUERTA 2) & PUERTA & 0,56 & 0,42 & 0,75 \\
\hline BINISSAFULET & TAULA & 0,38 & 0,59 & 1,55 \\
\hline COTAINA & TAULA & 0,59 & 0,66 & 1,12 \\
\hline SA TORRETA DE TRAMUNTANA & TAULA & 0,50 & 0,67 & 1,35 \\
\hline TALATÍ DE DALT & TAULA & 0,87 & 0,65 & 0,75 \\
\hline TORRALBA D'EN SALORT & TAULA & 0,58 & 0,66 & 1,13 \\
\hline TORRE D'EN GALMES & TAULA & 0,82 & 0,64 & 0,78 \\
\hline TORRELUSAR & TAULA & 0,63 & 0,48 & 0,75 \\
\hline TORRETRENCADA & TAULA & 0,71 & 0,63 & 0,89 \\
\hline TREPUCÓ & TAULA & 0,65 & 0,75 & 1,15 \\
\hline
\end{tabular}

Con los nuevos valores se ha ejecutado el test de Hotelling obteniendo como resultados un p-valor superior a $0,05(0,69)$. Esto indica que se acepta la hipótesis nula y en consecuencia se puede afirmar estadísticamente que taulas y puertas de los hábitats talayóticos son arquitectónicamente similares.

\subsubsection{Resultados}

El análisis estadístico realizado, aunque por el reducido tamaño muestral y la no aleatoriedad de la selección no es concluyente, sí que permite realizar inferencias con los resultados obtenidos. El test de Hotelling ha confirmado la similitud arquitectónica entre taulas y puertas talayóticas. A su vez, el análisis de covarianza reveló que, en la mayoría de las variables de ambas estructuras, aunque de magnitudes diferentes, se regían por los mismos principios de proporcionalidad. En conjunto, los datos obtenidos permiten defender que las taulas podrían haber sido representaciones simbólicas y monumentales de las puertas de los hábitats talayóticos.

\section{Discusión}

Existe consenso en la interpretación de los recintos de taula como edificios religiosos (e.g. Murray 1934; Plantalamor 1991; FernándezMiranda 2009). A grandes rasgos, en el contexto de la Antigüedad mediterránea, los templos constituyen lugares sagrados donde practicar el culto a los dioses, pudiéndose realizar sacrificios o dedicaciones votivas en honor a éstos, en señal de agradecimiento o con el fin de pedirles mediación (Glinister 1997). Además, estos lugares sacros podían servir como centros de encuentro donde fortalecer lazos entre sus usuarios y, en el caso de santuarios dotados de una gran monumentalidad, éstos se convertirían a su vez en formas de expresión del poder de una élite (Glinister 1997), encargada de su construcción y mantenimiento. Esta misma construcción reforzaría, a su vez, el sentimiento de identidad propia de la comunidad, junto con la aparición de otras monumentalidades concretizadas en otros espacios dentro del mismo núcleo poblacional. Pero dejando a un lado el aspecto social de un santuario de estas características, lo esencial, la comunión o encuentro directo entre lo humano y lo divino, es el factor primordial que determina la sacralidad. En el caso que nos concierne, tendría su epicentro en el elemento principal, la taula, que representaría una puerta de acceso al ámbito sacro. Como se verá, representaciones simbólicas parecidas se han utilizado en otras culturas del Mediterráneo en contextos funerarios, religiosos e incluso domésticos. 
Las puertas funcionales constituyen un elemento arquitectónico dotado de una gran carga simbólica en numerosas culturas, a causa de su doble carácter de espacio de tránsito y elemento de separación entre ámbitos con funciones diferentes. Así, en el planteamiento de Eliade (1981) de "la experiencia religiosa de la no homogeneidad del espacio" las puertas juegan un papel fundamental. En el plano cosmológico, la construcción de un muro con una entrada, que se abre generalmente bajo un dintel, implica la reducción a un punto concreto de la frontera entre dos planos de la realidad. El traspaso de la puerta se identifica con la transposición entre uno y otro de estos planos. Así, en las viviendas de las sociedades rurales, la puerta puede representar la separación entre el espacio humano, domesticado, y el espacio natural del exterior. En las comunidades urbanas, las puertas juegan un papel de gran relevancia en la vida de sus habitantes. Así, las puertas de las murallas (Marcos 2005) representan los puntos de conexión y separación con el exterior, donde se encuentran todo tipo de peligros. La puerta de la casa, por su parte, simboliza en muchos casos el límite entre el mundo exterior, colectivo, y el ámbito doméstico, de acceso más restringido. En los espacios religiosos, la entrada al edificio marca la separación entre el mundo profano y el sagrado pues, "pasar el umbral significa agregarse a un mundo nuevo" (Van Gennep 2008)

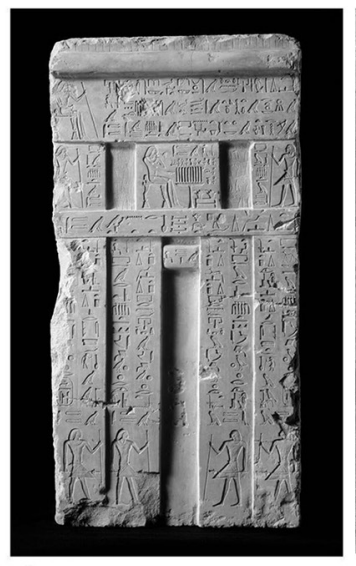

1

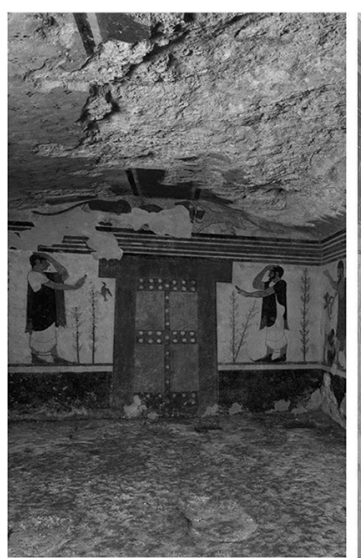

2
Esta carga simbólica de las puertas ha propiciado la aparición, en sociedades humanas de cronologías y contextos geográficos diversos, de puertas en las que el aspecto funcional ha desaparecido por completo. Es decir, se trata solamente de representaciones de puertas, sin una abertura física en el muro, que no pueden ser franqueadas de forma física por los seres humanos, pero sí, en la concepción cosmológica de estas comunidades, por las entidades incorpóreas capaces de transitar entre el plano natural y el plano sobrenatural de la realidad.

De este modo, las falsas puertas son un elemento simbólico que se documenta en otras culturas mediterráneas a lo largo de los últimos milenios anteriores al cambio de era, representadas tanto en bajorrelieves como en pintura mural. En el Egipto faraónico, estos elementos constituyen un tipo particular de estela, esculpida a partir de un bloque macizo de piedra, de tal forma que representara una puerta. Por esa razón se las ha llamado estelas falsa-puerta o puertas del $k a$ (Kanawati 1987; Vivas 2019). Se utilizaron durante un período amplio de la historia egipcia que va desde el Imperio Antiguo hasta el Imperio Nuevo (Redford 2001). En la mayoría de los casos, estas estructuras presentan jambas laterales y un dintel, elementos que permiten identificar el conjunto, de forma inequívoca, con una puerta.

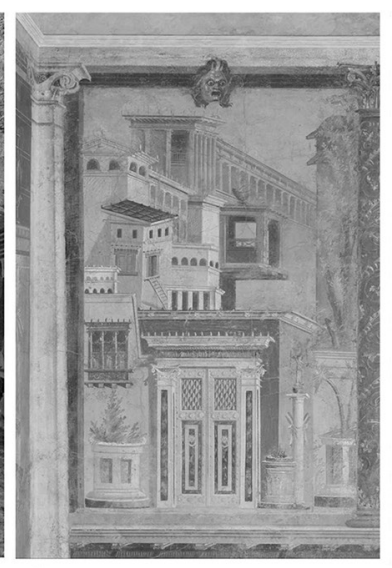

3

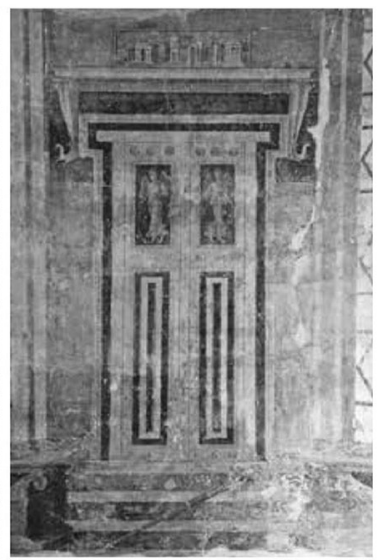

4

Figura 8. 8.1. Tumba de Metjetji (ca. 2353-2323 a.C.); 8.2. Tumba de los augures, Tarquinia (siglo VI a.C.); 8.3. Villa de P. Fannius Synistor, Boscoreale (s. I a.C.); 8.4. Villa de Popea, Oplontis (s. I a.C.)

La falsa-puerta de las tumbas egipcias (Fig. 8.1) tiene como objetivo permitir el paso del difunto hacia el inframundo (Redford 2001). La tumba "no se entiende como un bloqueo en- tre los mundos de los vivos y de los muertos, sino como una 'interfase' y la falsa puerta es el símbolo principal de ese aspecto" (Assmann 2003). La falsa puerta era, por tanto, el espacio 
de comunicación entre ambos mundos. Cabe destacar que este elemento cumple también con la función de establecer un vínculo permanente entre los dos planos, a través del cual el difunto puede recibir las ofrendas de los vivos en la otra vida (Bard 1992).

La falsa puerta es un elemento ritual que también se documenta en un contexto geográfico más próximo a Menorca, aunque más alejado de los recintos de taula a nivel cronológico: el neolítico final y el calcolítico de Cerdeña. En esta isla, desde principios del IV milenio cal $\mathrm{BC}$, se documentan las domus de janas, espacios funerarios excavados en la roca, que reproducen la arquitectura de las viviendas. En ellas aparecen frecuentemente representaciones de puertas, que han sido interpretadas también, a nivel simbólico, como el nexo entre el mundo natural y el sobrenatural (Spanedda 2013). En la iconografía de estas puertas destaca la representación de los dinteles, con decoración corniforme, que seguramente reproduce la decoración de los dinteles de las casas (Spanedda 2013).

Las representaciones simbólicas de puertas en espacios funerarios aparecen también en ámbitos más cercanos, cronológicamente, al de los recintos de taula de Menorca. Así, se trata de un motivo que se documenta, pintado, en algunas tumbas del siglo VI a.C. del mundo etrusco. Los ejemplares más destacables procedentes de la necrópolis de Tarquinia, como la tumba de los Augures y la de las Inscripciones (Blázquez 1957) donde las falsas puertas aparecen junto con elementos de clara temática funeraria como banquetes, juegos y danzas (Toynbee 1996) o incluso representaciones que claramente aluden al viaje al más allá (Torelli 1999).

En estas falsas puertas pintadas se enfatiza, como en el caso de las egipcias y sardas, el dintel y las jambas, como elementos que ayudan al observador a identificarlas con claridad (Fig. 8.2). Estas puertas parecen representar el paso del difunto al inframundo (Torresi 1994), que se encuentra al otro lado de una puerta que los vivos no pueden traspasar. Es interesante la similitud entre las casas etruscas y estos espacios funerarios (Blázquez 1957; OrtegaAndrade 1993), puesto que en las casas la habitación más importante, el tablinum o sala de recepción, se sitúa en el fondo en relación con la entrada principal de la casa. Este aspecto parece imitarse en las tumbas, donde la falsa puerta pintada se encuentra en la misma ubi- cación. Así, la cámara sepulcral de una tumba como la de los Augures representaría el atrio de una casa, mientras que la falsa puerta daría acceso simbólico a la morada del difunto (Blázquez 1957; Ortega-Andrade 1993).

Las representaciones de falsas puertas también aparecen en la esfera doméstica romana de los siglos en torno al cambio de era, con los ejemplos más destacados en las domus de la región de la Campania, en el sur de Italia. En estas falsas puertas, como en los ejemplos ya citados de otras culturas, se incluye el dintel y las jambas en su representación. Las pinturas que revisten el interior de las habitaciones de estas viviendas, lejos de ser tratadas como meras decoraciones encuadradas tipológicamente en los cuatro estilos pictóricos clasificados por August Mau (1899) y estudiadas en el contexto de su emplazamiento en el interior de un espacio doméstico privado, adquieren un significado mayor que el estético. Autores como Picard (1970) defienden que estas falsas puertas atienden a otras funciones relacionadas con la conexión entre el mundo privado y cotidiano con otros mundos externos, fuera de la casa propia e incluso de los límites de la ciudad. Esta postura parece estar justificada por el hecho de presentar algunas de estas puertas, en su parte superior, representaciones que permiten intuir al observador lo que hay al otro lado. Así, existen ejemplos donde la representación encima de la puerta es la de una calle con tumbas, como una de las cuatro puertas representadas en el atrio de la villa de Popea en Oplontis (Fig. 8.4). En otras ocasiones la parte superior de la puerta está coronada con la representación de templos, como en el caso de la habitación $\mathrm{M}$ de la villa de P. Fannius Synistor de Boscoreale (Fig. 8.3). Estos elementos, funerarios en unas ocasiones y religiosos en otras, podrían indicar la intención de conectar al morador de la vivienda con ancestros y divinidades.

Por supuesto, no existe ninguna conexión cultural directa entre las sociedades a las que pertenecen los ejemplos expuestos anteriormente y las comunidades menorquinas del Talayótico Final. Pese a todo, la presencia de elementos rituales tan parecidos en todas ellas parece indicar que el simbolismo de las puertas constituye un lugar común en los esquemas mentales del ser humano.

Al plantearse el porqué de la transformación de la puerta en un elemento puramente simbólico en el ámbito menorquín, cabe recor- 
dar que, en el periodo Talayótico Final, la importancia ritual de las puertas se percibe en la monumentalidad que adoptan estos elementos, presentando casi siempre jambas y dinteles monolíticos en los espacios domésticos.

Por otro lado, durante este periodo se documenta un cambio sustancial en el tipo de puerta que permite la entrada a los espacios funerarios. Así, los accesos de reducidas dimensiones de las navetas de habitación y cuevas naturales con cierre ciclópeo, propios de la fase precedente (Plantalamor 1991) dan paso a las grandes puertas de las cuevas artificiales de planta compleja, agrupadas generalmente en necrópolis. Los accesos a estas cavidades presentan en muchos casos puertas de dimensiones y proporciones parecidas a las de los espacios domésticos. Algunas de las puertas de acceso a estas cuevas presentan un complejo tratamiento decorativo del espacio que correspondería a las jambas y el dintel (Plantalamor 1991).

$\mathrm{Si}$, tal y como se propone en este trabajo, la taula es la representación simbólica de una puerta, constituye un caso ligeramente diferente a la mayoría de los ejemplos de otros contextos culturales, anteriormente expuestos, pues en esos casos las falsas puertas se vinculan generalmente a espacios funerarios, mientras que no existen evidencias que vinculen los rituales de los recintos de taula con rituales de este tipo. Pese a todo, y en sentido amplio, cualquier ritual religioso constituye una acción de comunicación entre el plano natural y el plano sobrenatural de la realidad, tanto si éste último se identifica con el mundo de ultratumba como si no. En este aspecto, la puerta entendida como símbolo de la vía de comunicación entre ambos planos es perfectamente compatible con las dos concepciones del mundo sobrenatural.

\section{Conclusiones}

La comparación entre la disposición de los elementos en los recintos de taula y las casas de planta circular permite proponer la existencia de un esquema espacial compartido entre ambos tipos de edificios. En dicho esquema, la taula y la puerta del espacio norte ocuparían posiciones equivalentes. La existencia de una serie de elementos arquitectónicos comunes a ambos tipos de edificios, así como el hecho de que estos ocupen una posición parecida con relación a la taula y a la entrada del ámbito norte, respectivamente, refuerzan esta lectura. Es el caso de las estructuras de combustión, las pilastras radiales, los pequeños bloques que flanquean la base de la taula y el acceso al ámbito norte o el propio acceso a los dos tipos de edificios. Por otro lado, la comparación entre las proporciones de los elementos constitutivos de taulas y puertas permite sostener que ambos elementos responden a los mismos principios de proporcionalidad.

En base a este enfoque, cabe plantearse cuáles serían las implicaciones sociales del paralelismo entre espacios domésticos y espacios rituales. Tal y como han manifestado algunos investigadores, las concepciones sociales y culturales de las comunidades humanas se manifiestan a través de la arquitectura doméstica (Rapoport 1969) o, dicho de modo todavía más explícito, las casas son espacios semánticos donde se escenifica el orden social (Gutiérrez 2012). Por otro lado, diversos autores han puesto de relieve la función del relato mítico como elemento de legitimación del orden y las estructuras sociales (e.g. Honko 1972). Partiendo de estas premisas, es posible proponer que el paralelismo entre la estructura de las casas de planta circular y los recintos de taula plasma la existencia de una correspondencia entre la estructura de los grupos domésticos y los esquemas religiosos de las comunidades menorquinas de la Edad del Hierro.

Se ha propuesto que la habitación norte de las casas de planta circular reúne las condiciones óptimas para servir de lugar de reunión, cohesión y representación social (Torres 2017). Pese a todo, y en el contexto de una sociedad estratificada (Guerrero, Calvo y Gornés 2006) parece razonable suponer que la heterogeneidad del espacio dentro de las viviendas se corresponde a una jerarquización del mismo. No todos los miembros del grupo doméstico tendrían acceso de forma igualitaria, por tanto, a todos los espacios de la casa. Así, es posible proponer una analogía entre la función de la habitación norte de las casas y la del espacio que se abre detrás de la taula: mientras que el primero de los espacios podría haber sido un espacio de reunión para algunos de los integrantes del grupo doméstico, el segundo lo sería para algunos de los integrantes de la comunidad. Cabe destacar que, mientras que en la fase precedente las tareas productivas parecen haberse organizado de modo colectivo (Anglada et al. 2012) durante el Talayótico Final las unidades básicas a partir de las cuales se 
articula la producción de algunos productos son los espacios domésticos. Así, en el interior de las casas se documenta el procesado de cereales (Ferrer 2011; Ferrer et al. 2011; Portillo et al. 2014) o la producción textil (Ferrer y Riudavets 2015) hecho que ha llevado a algunos autores a considerar estos espacios domésticos como núcleos de autoabastecimiento (Torres 2017). La estructura arquitectónica de estos edificios, cerrada hacia el exterior, pero abierta hacia el interior, parece reforzar esta lectura (Salvà y Hernández-Gasch 2007). Los recintos de taula, en este contexto, podrían constituir espacios de cohesión social para los representantes de grupos domésticos con un elevado nivel de autonomía a nivel productivo. Una de sus funciones, por tanto, sería la de reforzar los lazos de unión entre diferentes grupos de parentesco cercano dentro de un mismo poblado. Cabe recordar, en este sentido, que en el interior de algunos de estos edificios se han documentado acumulaciones de restos de caprinos domésticos y recipientes relacionados con el consumo de vino, que han sido interpretados como evidencias de banquetes rituales (Fernández-Miranda 2009). Bajo esta interpretación, la lectura del Edificio Sur de Cornia Nou como un precedente de los recintos de taula podría cobrar sentido a nivel funcional y no solamente desde el punto de vista arquitectónico. Durante el Talayótico Inicial, al menos en algunos casos como el de Cornia Nou, la cohesión entre los miembros de una comunidad implicaba el procesado colectivo de los productos agropecuarios en unos edificios concretos y específicos. Los cambios sociales del Talayótico Final trasladarían la gestión de dichos productos a los ámbitos domésticos, pero se habría mantenido un consumo ritual puntual de estos alimentos en unos edificios que conservaban algunas de las características de los espacios de trabajo colectivo de la etapa precedente.

A modo de síntesis, se puede afirmar que la tesis defendida en este trabajo permite entender los espacios rituales menorquines de la Edad del Hierro como un correlato de los espacios domésticos. Los recintos de taula se manifestarían, de este modo, como un modo de legitimación de las estructuras sociales. Así, tal y como han resaltado otros autores (Criado 2012) los espacios construidos, más allá de sus aspectos funcionales, deben ser interpretados como el resultado de una voluntad consciente de exhibición y de visualización, mediante el espacio, de un modelo social y cultural.

\section{Bibliografía}

Albero, D.; García, J.; Javaloyas, D.; Calvo, M. (2011): “Cultura material, habitus, espacio y movilidad en el archipiélago Balear durante el Bronce Final I (c. 1400-1100 BC)". Bolletí de la Societat Arqueològica Lul liana: Revista d'estudis històrics 67: 15-38.

Anglada, M.; Ferrer, A.; Plantalamor, L.; Ramis, D. (2017): "Continuïtat cultural en època de canvis: la producció i preparació d'aliments a Cornia Nou (Maó, Menorca) durant els segles IV-III aC". Menorca entre fenicis i Púnics. Menorca: Centro de Estudios del Próximo Oriente y la Antigüedad Tardía (CEPOAT): 137-156.

Anglada, M.; Ferrer, A.; Plantalamor, L.; Ramis, D.; Van Strydonck, M. (2012): “Arquitectura monumental y complejidad social a partir de finales del segundo milenio CAL BC: el edificio sur del sector oeste de Cornia Nou (Menorca)". Sardinia, Corsica et Baleares Antiquae: International Journal of Archaeology 10: 23-44.

Anglada, M.; Ferrer, A.; Plantalamor, L.; Ramis, D.; Van Strydonck, M. (2013): “La sucesión de ocupaciones entre el Calcolítico y la Edad Media en el yacimiento de Cornia Nou (Menorca, Islas Baleares)”. Espacio Tiempo y Forma 6: 267-296.

Anglada, M.; Ferrer, A.; Ramis, D. (2017b): “Actividad humana en el litoral de Menorca durante la Prehistoria. En: L. Gómez-Pujol; G.X. Pons (eds.), Geomorfología litoral de Menorca: dinámica, evolución y prácticas de gestión. Monografies de la Societat d'Història Natural de les Illes Balears. Palma de Mallorca: 213-233.

Assmann, J. (2003): “The Ramesside tomb and the construction of sacred space”. En: N. Strudwick Y J.H. Taylor, The Theban Necropolis. Past, Present and Future. British Museum. Londres: 46-52.

Barceló, J.A. (1988): "Introducción al razonamiento estadístico aplicado a la arqueología: un análisis de las estelas antropomorfas de la península ibérica". Trabajos de Prehistoria 45: 51-85.

Bard, K.A. (1992): "Toward an Interpretation of the Role of Ideology in the Evolution of Complex Society in Egypt". Journal of Anthropological Archaeology 11: 1-24. 
Blázquez, J.M. (1957): "Representaciones de puertas en la pintura arcaica etrusca". Trabajos de la Escuela Española de Arqueología en Roma 9: 49-74.

Cartailhac, É. (1892): Monuments primitifs des îles Baléares. É. Privat. Toulouse.

Ching, F.D.K. (2014): Architecture Form, Space, and Order. Wiley. New Jersey.

Criado, F. (2012): Arqueológicas, la razón perdida: la construcción de la inteligencia arqueológica. Bellaterra Arqueologia. Barcelona.

De Nicolás, J.C. (1995): Casa talaiòtica de Biniparratxet Petit. Aena-Aeropuerto de Menorca. Mahón.

Eliade, M. (1981): Lo sagrado y lo profano. Guadarrama. Madrid.

Fernández-Miranda, M. (2009): El poblado de Torralba d'en Salort (Alaior-Menorca). Fundació Illes Balears.

Ferrer, A. (2011): "El procesado de los cereales en Menorca (Islas Baleares, España) durante la Edad del Hierro. Una aproximación a partir de la etnología y la arqueología experimental." En: A. Morgado; J. Baena; D. García (eds.), La investigación experimental aplicada a la Arqueología. Granada: 179-184.

Ferrer, A.; Juan, G.; Lara, C.; Pons, J. (2011): "El jaciment de Torre d'en Galmés (Alaior, Menorca). Les intervencions d'Amics del Museu de Menorca: Cercle 7". III Jornades d'Arqueologia de les Illes Balears. Maó: Consell Insular de Menorca: 108-118.

Ferrer, A.; Riudavets, I. (2015): "Les fusaioles i els pesos de teler del Cercle 7 de Torre d'en Galmés: un exemple de la producció de teixits a Menorca durant la segona edat del ferro". En: C. Andreu; C. Ferrando; O. Pons (eds.), L'entreteixit del temps. Miscel-lània d'estudis en homenatge a Lluís Plantalamor Massanet. Palma de Mallorca: Govern de les Illes Balears: 163-173.

Glinister, F. (1997): "What is a sanctuary?". Cahiers du Centre Gustave Glotz 8 (1): 61-80.

Guerrero, V.M.; Calvo, M.; Gornés, J.S. (2006): Mallorca y Menorca en la Edad del Hierro. La cultura talayótica y postalayótica. Rey Sol. Historia de las Islas Baleares. Palma de Mallorca.

Gutiérrez, S. (2012): "Gramática de la casa: perspectivas de análisis arqueológico de los espacios domésticos medievales en la península ibérica (siglos VII-XIII)". Arqueología de la arquitectura 9.

Hochsieder, P. (2015): “Aspectes arqueoastronòmics a l'Edifici Sud de Cornia Nou (Menorca)". En: C. Andreu, C. Ferrando Y O. Pons (eds.), L'entreteixit del temps. Miscel-lània d'estudis en homenatge a Lluís Plantalamor Massanet. Govern de les Illes Balears. Palma de Mallorca: 221-232.

Hochsieder, P.; Knösel, D. (1995): Les taules de Menorca. Un estudi arqueoastronòmic. Mahón: Conselleria de Cultura, Educació i Esports. Govern Balear. Institut Menorqui d'Estudis. Menorca.

Honko, L. (1972): "The problem of defining myth". Scripta Instituti Donneriani Aboensis 6: 7-19.

Juan, G.; Pons, J. (2005): Talatí de Dalt 1997-2001, 5 anys d'investigació a un jaciment talaiòtic tipus de Menorca. Govern de les Illes Balears. Treballs del Museu de Menorca. Mahón

Kanawati, N. (1987): The tomb and its significance in Ancient Egypt. Foreign Cultural Information Department - Prism Publications. El Cairo.

Lilliu, G.; Schubart, H. (1967): Frühe Randkulturen des Mittelmeerraumes: Korsika, Sardinien, Balearen, Iberische Halbinsel. S.1.: Holle.

Marcos, M.A. (2005): "Ritos y creencias de la antigua Roma relacionados con las puertas". Revista de estudios latinos: RELat 5: 147-174.

Mascaró, J. (1969): "La taula como símbolo taurolátrico". X Congreso Nacional de Arqueología. Zaragoza: Secretaría General: 117-126.

Mau, A. (1899): Pompeii, its life and art. The Macmillan Company; Macmillan \& Co., ltd. New York, London

Micó, R. (2005): Cronología absoluta y periodización de la prehistoria de las Islas Baleares. BAR International Series, Archaeopress. Oxford.

Murray, M.A. (1934): Cambridge Excavations in Menorca. Sa Torreta. Imp. Wightman \& Co. Londres.

Murray, M.A. (1938): Cambridge Excavations in Menorca. Trapucó Part II. Imp. Wightman \& Co. Londres.

Ortega-Andrade, F. (1993): "La Construcción Etrusca (I)". Revista de Edificación 15: 55-62

Pérez-Juez, A.; Goldberg, P. (2018): "Evidence of Quarrying at the Iron Age Site of Torre d'en Galmés, Menorca, Spain”. Boletín Geológico y Minero 129 (1/2): 353-370.

Picard, G. (1970): Roman painting. Elek. Londres.

Plantalamor, L. (1987): "El santuario de So na Caçana y las relaciones con el Mediterráneo Central y Occidental". En: AAVV (ed.), Atti del II Convegno di studi "Un millennio di relazioni fra la Sardegna e i paesi del Mediterraneo: Selargius-Cagliari, novembre 1986. Selargius-Cagliari: Stef: 533-546. 
Plantalamor, L. (1991): Arquitectura prehistórica i protohistórica de Menorca i el seu marc cultural. Treballs del Museu de Menorca, 12. Maó.

Pons, J. (2016): Caracterització de l'espai de l'hàbitat protohistòric de l'illa de Menorca: les cases de planta circular talaiòtiques. Tesis Doctoral. S.1.: Universitat Autònoma de Barcelona.

Portillo, M.; Llergo, Y.; Ferrer, A.; Anglada, M.; Plantalamor, L.; Albert, R.M. (2014): “Actividades domésticas y molienda en el asentamiento talayótico de Cornia Nou (Menorca, Islas Baleares): resultados del estudio de microfósiles vegetales". Revista d'arqueologia de Ponent 24: 311-322.

Ramis, D. (2017): "Evidències de contactes exteriors al món talaiòtic a partir de l'estudi del registre faunístic. Menorca entre fenicis i Púnics». CEPOAT. Menorca: 201-217.

Rapoport, A. (1969): House form and culture. S.1.: Prentice-Hall.

Redford, D.B. (2001): The Oxford Encyclopedia of Ancient Egypt: Oxford University Press.

Rosselló-Bordoy, G. (1973): La Cultura Talayótica en Mallorca. Bases para el estudio de sus fases iniciales. Cort. Palma de Mallorca.

Salvà, B.; Hernández -Gasch, J. (2007): "Los espacios domésticos en las Islas Baleares durante las Edades del Bronce y del Hierro: de la sociedad Naviforme a la Talayótica". Actes de la IV Reunió internacional d'Arqueologia de Calafell (Calafell-Tarragona, 6 al 9 de març de 2007): Departament de Prehistòria, Història Antiga i Arqueologia: 299-322.

Sintes, E.; Isbert, F. (2009): "Investigación arqueológica y puesta en valor del Recinto Cartailhac: una unidad doméstica del siglo II ANE en el poblado talayótico de Torre de'n Galmés". Patrimonio cultural de España 1: 251-260.

Smith, A.; Van Dommelen, P. (2018): "Monumental Engagements: Cultural Interaction and Island Traditions in the West Mediterranean". En: A. Knodell y T. Leppard (eds.), Regional approaches to society and complexity: studies in honor of John F. Cherry. Monographs in Mediterranean archaeology (Equinox Pub.). Londres: 158-181.

Spanedda, L. (2013): "Las domus de janas sardas. Proyección de la «religión» y proyección de la estabilidad". Cuadernos de Prehistoria y Arqueología de la Universidad de Granada 19: 101-137.

Torelli, M. (1999): "Funera Tusca: reality and representation in archaic Tarquinian painting". En: C. Kondoleon, B.A. Bergmann, National Gallery of Art (U.S.) y Center For Advanced Study In The Visual Arts (U.S.) (eds.), The art of ancient spectacle. National Gallery of Art. London: 146-161.

Torres, O. (2017): ««Cercles menorquins»: aproximación a la influencia de la arquitectura púnica en las viviendas postalayóticas de Menorca». Menorca entre fenicis i púnics. Centro de Estudios del Próximo Oriente y la Antigüedad Tardía (CEPOAT): 231-243.

Torresi, A. (1994): Raffigurazione pittorica nella parete destra della Tomba degli Auguri. S.1.: Roma La Sapienza.

Toynbee, J.M.C. (1996): Death and Burial in the Roman World. JHU Press. Baltimore.

Van Gennep, A. (1909): Les rites de passage. Emile Nourry. París.

Veny, C. (1982): La necrópolis protohistórica de Cales Coves, Menorca. Consejo Superior de Investigaciones Científicas, Instituto Español de Prehistoria.

Vivas, T. (2019): La entrada al inframundo. Estelas de falsa puerta en el Antiguo Egipto. Dilema. Historiamayor. Madrid.

Waldren, W. (1986): The Balearic pentapartite division of prehistory: radiocarbon and other age determination inventories. BAR International Series 282. Oxford. 